Federal Reserve Bank of Minneapolis

Research Department Staff Report 142

July 1991

\title{
A RECONSIDERATION OF THE PROBLEM OF SOCIAL COST: FREE RIDERS AND MONOPOLISTS
}

\author{
V. V. Chari* \\ Larry E. Jones* \\ Federal Reserve Bank of Minneapolis \\ J. L. Kellogg Graduate School of Management
}

\begin{abstract}
We examine the validity of one version of the Coase Theorem: In any economy in which property rights are fully allocated, competition will lead to efficient allocations. This version of the theorem implies that the public goods problem can be solved by allocating property rights fully and letting markets do their work. We show that this mechanism is not likely to work well in economies with either pure public goods or global externalities. The reason is that the privatized economy turns out to be highly susceptible to strategic behavior in that the free-rider problem in public goods economies manifests itself as a complementary monopoly problem in the private goods economy. If the public goods or externalities are local in nature, however, market mechanisms are likely to work well.

Our work is related to the recent literature on the foundations of Walrasian equilibrium in that it highlights a relationship among the appropriateness of Walrasian equilibrium as a solution concept, the incentives for strategic play, the aggregate level of complementarities in the economy, and the problem of coordinating economic activity.
\end{abstract}

*As will be apparent to most readers, we owe much to Hugo Sonnenschein for this paper. He shaped our thinking about this problem greatly through his 1983 Nancy L. Schwartz Lecture, "The Economics of Incentives: An Introductory Account." Thanks are due to Mort Kamien for introducing us to Cournot's (1838) Chapter 9 which formed the basis for many of our insights. We thank Leo Hurwicz, Andreu Mas-Colell, Joe Ostroy, and Hugo Sonnenschein, the panelists at the Special Session on Decentralization, North American Summer Meetings of the Econometric Society, June 1988, for useful comments. Finally, thanks are due to John Ledyard, Rodolfo Manuelli, Edward Prescott, Ariel Rubinstein, and Joel Sobel for many useful and encouraging conversations. Larry Jones thanks the National Science Foundation and the Sloan Foundation for financial support.

The views expressed herein are those of the authors and not necessarily those of the Federal Reserve Bank of Minneapolis or the Federal Reserve System. 


\section{Introduction}

Over the years, two approaches to the allocation of resources for the provision of public goods have evolved. The first approach, identified loosely with Coase (1960), holds that if there is a problem at all, it is that property rights are not fully assigned and moreover, if they were, competition would lead to an efficient allocation. This statement has come to be known as the Coase Theorem. The second approach, even more loosely associated with Samuelson (through his 1954 paper), espouses quite a different view, holding that individuals will strategically misrepresent their true desires regarding the provision of public goods. This free-rider problem will lead to inefficient public goods provision.

These two schools of thought have strikingly different implications for public policy. According to the first, nothing need be done save to develop a system for the full assignment of property rights. (Perhaps the judicial system is expected to serve this purpose.) According to the second, the government has an important role in actively participating in the provision of public goods.

This difference of opinion would not matter if it could be clearly identified that one or the other of the approaches was right. The problem is that both approaches have intuitive appeal. In particular, one can think of examples in which it seems likely that the Coasian policy recommendation would be successful. Classic examples include that of the beekeeper and the apple orchard owner (Meade (1952)) and that of the candy maker next to the doctor (Coase (1960)). In other examples, such as acid rain and national defense, it seems likely to fail. The ideal theory would give the intuitively correct prediction for each of these examples.

The ultimate goal is to develop a taxonomy that could be used to classify economic situations to decide which of the above approaches is appropriate. We will fall considerably short of that goal, but we hope our results shed some light on the issue. 
To develop a further understanding of the Coase Theorem, we will have to be precise about both the meaning of the full assignment of property rights and the nature of competition in the marketplace. We address the property rights issue by recasting an economy with externalities as a private goods economy in which endowments play the role of property rights. We address the competition issue by considering a large class of theories of decentralized exchange, each of which is explicit about strategic interactions between agents. In doing so, we borrow heavily from the literature on mechanism design (Hurwicz (1972)). This literature allows us to represent a large class of theories by axioms on abstract mechanisms. We argue that our class of theories provides a description of the workings of market-like arrangements. We show that all of the theories in our class predict the same outcome: market-like arrangements provide extremely inefficient levels of public goods. An interesting feature of our analysis is that it identifies the free-rider problem in a public goods environment with a complementary monopoly problem in the private goods economy. Our analysis also suggests that this monopoly power diminishes when the public goods are local, a result reminiscent of Tiebout (1956). Thus, when public goods are local, market mechanisms seem likely to work well.

Section 2 develops three illustrative examples. These serve as a motivation for the subsequent, more general, development. In Section 3, we prove several results that show how the free-rider problem manifests itself as a complementary monopoly problem in privatized public goods economies with complete information. These results show that for a large class of mechanisms the outcome is the least efficient one consistent with individual rationality and feasibility. The mechanisms in this class are required to satisfy a strong assumption of voluntary trade. This assumption gives monopoly power to individuals and leads to inefficient outcomes. In Section 4, we give two generalizations of the results of Section 3 when tastes are private information. We replace the strong notion of voluntary trade by the standard assumption of individual rationality in 
private information economies and show that outcomes are extremely inefficient. Private information turns out to confer monopoly power to individuals. Taken together, the results in Sections 3 and 4 show that there is a tradeoff between the strength of informational assumptions and restrictions placed on mechanisms. Section 5 considers alternative distributions of property rights and identifies a slightly different type of free-rider problem. Section 6 offers concluding comments.

\section{Examples}

We begin with a simple standard example. We follow the approach to the problem suggested above-we start with an economy with an obvious externality, add the needed markets, assign the property rights for these new goods, posit a form for competition, and calculate the equilibrium.

Example 1: Consider an economy in which there is a town with a number of firms, each producing the same final product for sale to an external market. Assume that each producer owns a factory that produces smoke in addition to the output. Assume that the smoke emanating from each factory spreads uniformly over all locations throughout the town and is (for simplicity) proportional to the output of the factory. Then the total smoke over any location in the town is proportional to the total output of the industry. Assume that each firm can produce as much of the output as it likes at zero marginal cost and that demand for the final product is linear in price:

$$
\mathrm{D}(\mathrm{p})=\mathrm{a}-\mathrm{bp},
$$

where $\mathrm{a}>0, \mathrm{~b}>0$, and $\mathrm{a}>\mathrm{b}$. We assume that the firms are perfect competitors in the output market. We could formalize this assumption through Bertrand price competition among any finite number of firms or approximate it arbitrarily well by assuming quantity competition among a very large number of firms. 
Finally, we assume that there are $\mathrm{n}$ residents in the town. We assume for simplicity that the residents have utility functions over money $m$ and smoke consumption $s$ of the form $U(m, s)=$ $\mathrm{m}-(\mathrm{s} / \mathrm{n})$. (We will see in a moment why it is $\mathrm{s} / \mathrm{n}$ and not $\mathrm{s}$. )

The equilibrium for this example is clear: $\mathrm{p}^{*}=0$, aggregate output of both the final good and smoke is a, and the utility of the residents is $m^{*}-a / n$, where $m^{*}$ is the initial allocation of money. The example is standard enough; in their calculations of profit-maximizing production plans, the firms ignore the social cost of their production of smoke, thereby imposing an externality on the residents. Thus, the market acts as if the marginal social cost of both output and smoke is zero while in reality it is $\$ 1$ ( $\$ 1 / \mathrm{n}$ of disutility to each resident for each unit of smoke produced).

In terms of the Coase Theorem, the problem in this economy is that no markets for pollution over the homesites exist. The solution is equally straightforward: Introduce such markets, and let competition proceed as usual. Here we run into problems. First, how do we formally treat these goods in both production and consumption? And second, how are the endowments of these new goods to be assigned, and what are their initial quantities? To address these questions, we will have to be a little more formal and introduce a little more notation.

Let each household be endowed with $S$ units of smoke rights, where $S$ is a large positive number (at least as large as a). Smoke rights are a "good" rather than a "bad" from the residents' point of view. We define preferences over smoke rights as follows. The utility of a resident who sells s units of smoke rights in this private goods economy is

$$
\mathrm{U}^{\mathrm{i}}(\mathrm{m}, \mathrm{s})=\mathrm{m}+(\mathrm{s}-\mathrm{s}) / \mathrm{n}
$$

Thus, utility is increasing in the consumption of smoke rights. (Note that if all of an individual's smoke rights are used in production, then in effect the utility function in the externalities economy is scaled up by $S / n$.) 
Each firm must purchase one unit of each smoke right to produce one unit of output. We have defined a private ownership economy with perfect complementarities for which the nonwasteful allocations coincide with the feasible allocations of a public goods economy. (Foley (1967), Milleron (1972), and Starrett (1972) used this connection between public goods economies and perfect complementarities in private goods economies as a device to facilitate the proof of the existence of Lindahl equilibrium. However, they did not exploit the relationship between this equivalence and problems of market power.) In keeping with the spirit of competitive product markets, we assume that the firms take the prices of the smoke rights as given.

In the perfectly competitive outcome, each of the smoke rights sells for a price $\mathrm{p}_{\mathrm{j}}=1 / \mathrm{n}$ and the final good sells for $p=1$, and quantities $a-b$ of the final product and of each of the two types of smoke are produced. It is easy to see that this equilibrium is efficient (and is the Lindahl equilibrium of the original economy).

Given that the markets for the individual smoke rights are so thin, the assumption of price-taking behavior is questionable. For this reason, we examine a different, more strategic, notion of equilibrium. Note that this approach is not contrary to Coase's original intent in any way. In fact, Coase seemed to think that efficient allocations would arise out of bargaining between the parties (although exactly what he had in mind is unclear).

For the moment, we assume that competition takes the form of residents setting prices for their site-specific smoke rights. Residents are fully cognizant of the effects of their decisions on the production of the final good as well as their neighbors' incentives. Thus, if resident i prices his or her smoke rights at $\mathrm{p}_{i}$, then firms act as if their marginal cost of production is $\sum_{i=1}^{n} p_{i}$. In this case, the price in the final good market is $\Sigma p_{i}$ (because of our assumption of perfect competition in the final good market). Then output is $q(p)=a-b\left(\sum p_{i}\right)$, and revenues from sales of smoke 
rights for the households are $r_{i}=p_{i} q(p)$, giving utility $m^{*}+r_{i}+(S-q) / n$. It is straightforward to check that, given the prices set by other residents, the best price for resident 1 is given by

$$
p_{1}\left(p_{-1}\right)=\frac{1}{2 b} a+\frac{b}{n}-b \sum_{i \neq 1} p_{i}
$$

It follows that the equilibrium prices for smoke rights are given by

$$
\mathrm{p}_{\mathrm{i}}=\frac{\mathrm{a} / \mathrm{b}+1 / \mathrm{n}}{\mathrm{n}+1}
$$

for all $\mathrm{i}$. Hence, from the firms' point of view, the marginal cost of production (and hence the price of the final good as well) is

$$
\mathrm{p}=\frac{\mathrm{n}}{\mathrm{n}+1} \frac{\mathrm{a}}{\mathrm{b}}+\frac{1}{\mathrm{n}}
$$

Note that the price of the final good is greater than 1 , which is the Lindahl equilibrium price, and that the quantity produced is less than the Lindahl equilibrium quantity.

In this example, in effect, each resident is selling an output that costs $\$ 1 / \mathrm{n}$ per unit to produce (the dollar cost of the loss of one unit of smoke rights) and is maximizing profits. If the residents could get together and sell their inputs to the firms jointly, they could do much better. In this case, the best price for them to charge is $(1+\mathrm{a} / \mathrm{b}) / 2 \mathrm{n}$ apiece, which gives a final product price of $(1+a / b) / 2$ which is less than the equilibrium price in (2.3).

As another point of comparison, consider the case where the residents are not adversely affected by smoke at all (i.e., utility is given by $U(m, s)=m$ ). In this case, a simple calculation shows that the equilibrium price of the smoke rights is $p_{i}=a /(n+1) b$. Then the marginal cost of production of the final good (and its price) is given by $(n / n+1)(a / b)$. Note that this price 
exceeds even the monopoly price of the output (which is $a / 2 b$ ). Thus, the equilibrium is even less efficient than monopoly when we use the standard measure of producer plus consumer surplus.

That the equilibrium is inefficient is probably not surprising since we have given the residents an element of monopoly power which they exploit. In light of this, a natural question to ask is whether the monopoly power diminishes as the number of residents is increased. From (2.3) we see that as the population increases, the equilibrium price of the final product converges monotonically to the reservation price, $a / b$. So as the population increases, output of the industry and, therefore, production of smoke converges monotonically to zero. The monopoly power, instead of diminishing, causes output to deviate far from the efficient level.

Note that through our choice of normalization, we have constructed a sequence of economies in which the Lindahl equilibrium is unchanged as a function of the population size $n$, in the sense that the output and price of the final product are independent of $n$. Of course, the prices of the individual smoke rights do change with the population size as they are given by $1 / \mathrm{n}$ in the nth economy. (Thus, we have adopted the normalization recommended by Milleron (1972). Roberts (1976) uses an alternative normalization in which the reservation price is $\mathrm{na} / \mathrm{b}$ and $\mathrm{U}=\mathrm{m}-\mathrm{s}$ for all n.)

Example 2: In Example 1, residents of the town have property rights to the air quality over their land. As we saw, this gives each resident a monopoly over the air quality over his or her plot of land. An obvious question is, To what extent are the problems identified in the strategic formulation of Example 1 a product of this monopoly power? To answer this question, we consider an economy where the property rights to air quality over a particular plot of land are not distributed to the owners of the land. Rather, they are distributed to a third party (or group of third parties) who neither resides in the town nor consumes the output of the industry. The third party sells the 
rights to produce (and hence pollute) to both the residents of the town and the firms producing the final output. The third party can be interpreted either as the government or as individuals. The purpose of this exercise is to ask whether, in this situation, residents of the town have sufficient incentives to buy these rights so as to reduce pollution and whether or not this procedure will generate efficient outcomes.

The demand function is the same as in Example 1. The amount of the property rights distributed to the third party is the same for each plot of land and is denoted by S. We assume that $\mathrm{S} \leq \mathrm{a}$. The utility of a resident who consumes $\mathrm{m}$ units of money and $\mathrm{x}$ units of smoke rights is given by $U^{i}(m, x)=m+x / n$.

As in Example 1, firms must purchase one unit of each type of smoke right to produce one unit of output. Thus, the complementarity between the smoke rights as productive inputs remains though the initial ownership is different.

If $S$ is at least as large as $a-b$ (the Lindahl equilibrium output level), then it is easy to show that the perfectly competitive equilibrium outcome is the Lindahl equilibrium. Each resident purchases $S-(a-b)$ units of smoke rights over his or her land, and firms purchase the rest. Each of the individual smoke rights is priced at $1 / \mathrm{n}$, which results in an equilibrium price of 1 for the final output as in the previous example.

We turn now to a strategic formulation of this economy. To focus attention on the nature of the strategic behavior of the town residents, we adopt the simplifying assumption that firms, purchasers of the final good, and owners of the smoke rights behave as price takers. We allow residents to buy smoke rights only over their own land. For simplicity, we analyze a price game in which residents act as price leaders with the output market acting as a competitive fringe. The owners of the smoke rights sell these rights inelastically. Accordingly, each resident sets a price, $\mathrm{p}_{\mathbf{i}}$, for the smoke rights over his or her plot of land. Let $\mathrm{P}$ denote the vector of these prices. 
Because the firms must buy one unit of each of the smoke rights for each unit of output produced, their marginal cost of production is $\Sigma \mathrm{p}_{\mathrm{i}}$. It follows that the price of the final output is $\mathrm{p}=\Sigma \mathrm{p}_{\mathrm{i}}$, and thus output is given by $q(P)=a-b \sum p_{i}$. Each resident therefore purchases $S-q(P)$ units of smoke rights and pays $p_{i}(S-q(P))$. The utility of household $i$ is thus

$$
\mathrm{U}^{\mathrm{i}}=\mathrm{m}^{*}-\mathrm{p}_{\mathrm{i}}(\mathrm{S}-\mathrm{q}(\mathrm{P}))+(\mathrm{S}-\mathrm{q}(\mathrm{P})) / \mathrm{n} .
$$

Given the prices set by the other residents, the best price for resident 1 is then

$$
p_{1}\left(p_{-1}\right)=1 / 2 b\left[a-S+b / n-b \sum_{i \neq 1} p_{1}\right]
$$

if $S \geq a-b$. If $S<a-b$, then resident 1 sets the price according to

$$
p_{1}\left(p_{-1}\right)=\max \left\{1 / b\left[a-s-b \sum_{i \neq 1} p_{i}\right], 1 / 2 b\left[a-s+b / n-b \sum_{i \neq 1} p_{i}\right]\right\}
$$

From (2.4) it is straightforward to calculate that the equilibrium prices are

$$
\mathrm{p}_{\mathrm{i}}=\{[(\mathrm{a}-\mathrm{S}) / \mathrm{b}]+(1 / \mathrm{n})\} /(\mathrm{n}+1)
$$

if $S \geq a-b$.

It follows that the marginal cost of production-and, hence, the price of the final product-is given by

$$
\sum \mathrm{p}_{\mathbf{i}}=\mathrm{n} /(\mathrm{n}+1)\{[(\mathrm{a}-\mathrm{S}) / \mathrm{b}]+(1 / \mathrm{n})\}
$$

if $S \geq a-b$.

In equilibrium the residents buy $S-q(P)$ units of smoke rights. Using the demand curve, we see that this quantity is 


$$
S-q(p)=(S-(a-b)) /(n+1)
$$

if $S \geq a-b$.

It is easy to show that if $S<a-b$, in equilibrium the residents do not purchase any smoke rights.

From (2.6), we see that as the population grows, the amount of smoke rights residents purchase converges to zero. Therefore, production reaches the maximum level possible given the initial distribution of smoke rights.

This example illustrates that the efficient level of smoke will not be produced under alternative property rights systems unless the amount auctioned off is chosen correctly, that is, unless $\mathrm{S}=\mathrm{a}-\mathrm{b}$. In particular, schemes that distribute large quantities of pollution rights in the hope that residents will restrict output to the optimal level through their voluntary purchases will not work in general. In one such scheme, for example, firms are allocated pollution rights according to their historical level of output and trade is then allowed. Such schemes may be superior to direct regulation of output in that they are likely to promote allocative efficiency across firms, but they will not yield the efficient level of pollution overall. Schemes that require voluntary contributions in order to reduce the overall level of pollution will be inefficient because they create free-rider problems. When individuals choose their levels of contributions, they ignore the benefits received by others from the resulting reduction in output. Therefore, they contribute less than the optimum amount. In essence, this alternative distribution of property rights changes the nature of the problem from one of externalities to one of public goods. Therefore, although the outcomes differ, the inefficiency remains. 
Example 3: Our third example is a slight modification of Example 1. Consider an economy like that considered in Example 1 except that there are two towns, each with $\mathrm{n}$ residents and many price-taking producers of the final product. To make the problem as simple as possible, we abstract away from the fact that the final product is now being produced at different locations. That is, we proceed as if transportation costs for the final product are zero, and hence consumers treat output from the two locations as perfect substitutes. This assumption is roughly equivalent to assuming that neither town has a specific productive advantage over the other. It is, of course, a strong assumption, but one that greatly simplifies our exposition.

Assume that demand for the final good is as in Example 1. Finally, assume that smoke from the factory in one town has no effect on the residents of the other town.

The economy without smoke rights clearly has many competitive equilibria which differ only in the proportion of final output produced in the two towns. That is, in all of the equilibria, $\mathrm{p}^{*}=0$ and $\mathrm{q}^{*}=\mathrm{a}$, but any combination of quantities that add up to a can arise in equilibrium.

Now let us introduce individualized pollution markets as we did in Example 1. A fundamental difference between this economy and the one we considered earlier is that in order to produce a unit of output, a firm need not buy one unit of smoke rights from each household; rather, it need only purchase one unit from each household in the town in which it plans to produce. Clearly, this difference could have a substantial impact on the nature of the equilibrium: now firms may be able to get residents in the two towns to compete against one another in pricing their smoke rights. Note that in some sense markets are just as thin as they were before-individuals still have monopoly power over the smoke rights at their individual locations-but now these products are no longer as complementary. In fact, there is now a perfect substitute for each of the smoke rights and, moreover, a perfect substitute for an exhaustive list of the smoke rights of each town. In other words, there is now a perfect substitute for each of the two production sites (i.e., towns). 
Formally, let $S-s_{i}$ be the amount of smoke rights consumed by resident $i, i=1, \ldots$, $2 \mathrm{n}$, where for simplicity we will assume that residents 1 through $\mathrm{n}$ live in town 1 and the rest live in town 2. The utility functions are given by

$$
\mathrm{U}_{\mathrm{i}}\left(\mathrm{m}, \mathrm{s}_{1}, \ldots, \mathrm{s}_{2 \mathrm{n}}\right)=\mathrm{m}+\frac{\left(\mathrm{S}-\mathrm{s}_{\mathrm{i}}\right)}{\mathrm{n}}
$$

It is immediate that the Lindahl equilibria (there are many) of this economy have each smoke right priced at $1 / \mathrm{n}$ and the final output priced at 1 .

As before, we assume that residents set prices for their individual smoke rights, which the producing firms then take as given. We assume that firms are already producing in both towns. (This assumption is irrelevant; we could have them choose their sites as a function of the announced smoke rights prices, with the same result.) We also assume that, as before, firms behave as perfect competitors in that they charge marginal cost for their output. We assume that only output from the town with the lower cost of production is sold and that, in case of ties, the market is split evenly. (These assumptions are familiar in economics; we discuss them in more detail below.)

Letting $p_{i}$ be the price announced by resident $i$ and $\Pi_{1}$ be the sum of the prices in town 1 and $\Pi_{2}$ the sum of the prices in town 2 , we see that the payoff to resident $i$ as a function of the announced prices is then

$$
U_{i}\left(p_{1}, \ldots, p_{2 n}\right)-S / n=\left\{\begin{array}{ll}
m_{i}+\left(a-b \Pi_{1}\right)\left(p_{i}-1 / n\right) & \text { if } \Pi_{1}<\Pi_{2} \\
m_{i}+\left(a-b \Pi_{1}\right)\left(p_{i}-1 / n\right) / 2 & \text { if } \Pi_{1}=\Pi_{2} \\
m_{i} & \text { if } \Pi_{1}>\Pi_{2}
\end{array}\right\}
$$

for $\mathrm{i}=1, \ldots, \mathrm{n}$ and similarly for $\mathrm{i}=\mathrm{n}+1, \ldots, 2 \mathrm{n}$. 
The Lindahl equilibrium (i.e., $\mathrm{p}_{\mathrm{i}}=1 / \mathrm{n}$ for all $\mathrm{i}$ ) for this economy is clearly a symmetric equilibrium of the game as given: if any resident raised his or her price, no production would take place in that town and hence the resident would be no better off than before; of course, no residents would lower their price. It turns out that this is the only symmetric equilibrium for the game in which output of the final product is positive. The argument for this result is familiar. If all charge some price higher than $1 / \mathrm{n}$, then any individual can bring all of the production of the industry to his or her town by lowering his or her own price only slightly. Since the marginal benefit of this change is 1 and the marginal cost is $1 / \mathrm{n}$, the individual will be better off by making this change.

There are at least two other types of equilibria as well. These arise due to the difficulty of coordinating price offers among residents in a town. First, suppose that for all combinations of $\mathrm{n}-1$ residents of each town, the sum of the offered prices is larger than the reservation price, $a / b$. Then no individual resident can, by lowering the price unilaterally, lower the marginal cost of production in his or her town to the point that any firm could break even and sell a positive quantity. Second, if all of the residents of one town charge the one-town equilibrium prices outlined in Example 1, and all groups of $\mathrm{n}-1$ residents of the other town charge prices summing to more than that of the first town, then we have an equilibrium with production in only one town. Again, since no individual in the second town can lower his or her price enough unilaterally, there will be no production in that town.

We can also consider alternative distributions of property rights for this example as we did in Example 2. Again, consider a game where residents of each town set prices for smoke rights and firms, consumers, and sellers of smoke rights behave competitively. Efficient outcomes can be supported by an equilibrium where residents of both towns set prices for smoke rights at $1 / \mathrm{n}$, production is split evenly, and the price of the final good is 1 . This is an equilibrium because by lowering the price, a resident can bring all production to his or her town, and by raising the price, 
the resident can move all production to the other town. The change in revenues is of order 1 and the change in the cost of pollution is of order $1 / \mathrm{n}$.

\section{Some Comments}

(i) Cournot (1838, Chapter 9), in fact, considered a version of Example 1 in a quite different setting. He framed the problem as one of complementary monopoly. In his model a monopolist producer of zinc and a monopolist producer of copper produce for a perfectly competitive market for brass. He assumed that demand for the final product (brass) was linear and that copper and zinc could be used only to produce brass. This model is formally equivalent to our Example 1. Note that Cournot considered the analogue of our case in which the disutility from smoke on the part of the residents is zero.) In addition, Cournot considered the n-input complementary monopoly problem analogous to our first example and obtained similar results. An interesting feature of our Examples 1 and 2 is that they illustrate that complementary monopoly problems are pervasive in privatized public goods economies. The problems caused by complementarities are recurrent themes in the literature on the foundations of perfect competition. Examples include Hart (1980), Makowski (1980), and Jones (1987a) and (1987b) in addition to Cournot (1838).

(ii) Many readers may not find Example 1 too surprising. Even with many residents, the markets for smoke rights are highly individualized and hence intrinsically thin. Thus, although it might be surprising that the problem gets worse as the number of residents grows, it should not be surprising that the inefficiency does not go away. As Arrow (1970) argues, although you can get rid of an externality problem by creating markets for pollution rights, these markets are likely to be thin, so that perfect competition may not be the correct notion of equilibrium to employ.

One should not make this judgement too hastily, however. Just because only one individual is selling in the market for the individualized smoke rights does not necessarily imply that 
the individual has market power to exploit. Indeed, the model examined in Mas-Colell (1975), Hart (1979), and Jones (1987a) is an example in which each individual has sole ownership of some good, yet because good substitutes exist, the individuals have no market power. To see that monopoly power does not necessarily imply market power, note that the thin-markets argument by itself would lead one to believe that individual residents have market power in the local real estate market as well. This will not be true, however, if the number of sellers is sufficiently large and potential residents regard different plots of land as good substitutes. All this is not to say that the thin-markets argument is wrong. We just want to point out that it is much too subtle an issue to pass over without thought. Example 3 further illustrates this point. Each resident in a town has a monopoly over his or her smoke rights but no market power because of competition from residents of the other town. In summary, the complementarity of the goods in the production process plays a crucial role in the examples.

(iii) The results of Example 1 might be expected for another reason familiar to those in public finance. A simple reinterpretation of our game will make this clear. Instead of assigning property rights and letting residents price these rights as they see fit, suppose we assume that each resident announces per-unit damages due to the smoke over his or her property and is paid this amount times the total quantity of smoke produced. This restitution program is financed by an ad valorem tax equal to the total per-unit damage announced. If we maintain our assumptions that firms in the output market are perfect competitors and that residents fully and correctly anticipate the effects of their announcements on the output market, then this game and that in our examples are formally equivalent.

Of course, no one should be surprised that the outcome of the game when stated in this way is inefficient: there is a free-rider problem. The same free-rider problem shows up in Example 
2 , in which residents pay firms to reduce pollution. The residents have incentives to understate their marginal disutility to take a free ride on the reduction in pollution due to other people's payments. Thus, it should be no surprise that the inefficiency does not go away in large economies; this is exactly the situation in which the free-rider problem is commonly believed to be most severe.

(iv) The role of the strategic formulation of the equilibrium problem considered here is interesting. The price-taking and price-setting equilibria differ in efficiency because of differences in perceptions about the constraints facing decision makers. That is, in the price-taking version of the economy, agents act as if they could set smoke levels independently of the actions of the other agents. The fact that this is not possible is imposed only in equilibrium, not in the individual decisions. Introducing strategic play restores these social constraints in the individual decision makers' problems and produces the adverse effects on welfare.

(v) We can now give a better (though still very imperfect) summary of the role of market mechanisms in providing public goods. Example 1 shows that such mechanisms will not work in full generality. Further, it is clear that such mechanisms can do very badly in large economies. Taken together, however, the examples suggest that the problem in the large economies result of Examples 1 and 2 is the high degree of complementarity. Further, Example 3 suggests that the Coase mechanism (and perhaps other mechanisms as well) may allocate the costs of externalities reasonably well in an interesting class of large economies. We should emphasize at this point that this seems to be limited to those economies in which both the externalities are local in nature and there are many potential locations. Thus, for example, it seems quite plausible that the mechanism will work for Meade's (1952) beekeeper and apple orchard example. (If the price charged by the orchard owner is too high, go to another orchard.) The mechanism might also work in Coase's (1960) candy maker and noise creation example. (Move the candy factory, or move the doctor.) 
It seems highly unlikely to represent a reasonable solution to either the acid rain problem or the problem of allocating funds for national defense.

The force of the local public goods result is very much in the spirit of Tiebout (1956). Unlike Tiebout, however, we do not require mobility of residents across locations to generate good outcomes with local public goods.

\section{A More General Approach}

The examples of the previous section suggest two possible approaches to the public goods problem. The first approach is to ask how a central authority might ensure efficient public goods provision by designing a set of rules restricting the behavior of private agents. This approach has been extensively explored in the mechanism design literature (e.g., Hurwicz (1972), Groves and Ledyard $(1977,1985))$. The second approach is to ask what outcomes market-like arrangements will produce.

We take the second approach. We must first take a stand on what constitute the key features of market-like arrangements. The mechanism design literature provides a convenient language for this purpose. We formalize market-like arrangements by considering a large class of mechanisms sharing two key properties: a strong notion of property rights and a uniform continuity requirement. We show that if a mechanism satisfies these two properties, decentralized voluntary exchange under such a mechanism leads to extremely inefficient outcomes. This approach generalizes Example 1 to a larger class of models of strategic interaction.

We consider a more general environment than in the examples. The commodity space

is $\mathbf{R}^{\mathbf{n}+1}$. The last commodity is interpreted as a numeraire consumption good. The remaining commodities, $\mathrm{i}=1, \ldots, \mathrm{n}$, are interpreted as consumption of smoke rights. There are $\mathrm{n}$ consumers with consumption sets $X_{i}=\mathbf{R}_{+}^{\mathbf{n}+1}$. The preferences of consumer $\mathbf{i}$ are given by 


$$
\mathrm{V}_{\mathrm{i}}(\mathrm{x})=\mathrm{x}_{\mathrm{n}+1}+\mathrm{u}_{\mathbf{i}}\left(\mathrm{x}_{\mathbf{i}}\right)
$$

Notice that consumers care only about consumption of their own smoke rights, that is, smoke produced over their own location. Let $x_{j}^{i}$ denote the consumption of good $j$ by consumer $i$. The endowment vector of consumer $i$, denoted by $w^{i}$, is given by

$$
w_{i}^{i}=\bar{q}_{i}>0, \quad w_{n+1}^{i}=\bar{m}_{i}>0
$$

for all $i$ and

$$
w_{j}^{i}=0
$$

for $\mathrm{i} \neq \mathrm{j}, \mathrm{j}=1, \ldots, \mathrm{n}$. The technology set for this economy is given by

$$
Y_{n}=\left\{y \in R^{n+1} \mid y_{1}=y_{2}=\ldots=y_{n}=-q ; y_{1}, y_{2}, \ldots, y_{n} \leq 0, y_{n+1} \geq 0, R(q) \geq y_{n+1}\right\} .
$$

Note that the endowments (which are the property rights) convey to each agent monopoly power over smoke produced at the agent's location. The complementarities inherent in public goods are captured in the description of the technology. To relate this economy to the demand functions specified in the examples, we can set $R(q)=q D^{-1}(q)$.

An allocation is feasible if

$$
\sum_{i=1}^{n} x^{i}-y=\sum_{i=1}^{n} w^{i}
$$

and

$$
\mathrm{y} \in \mathrm{Y}_{\mathrm{n}}
$$

From this description, it is easy to construct an economy with externalities as in the examples of the previous section. The two economies are equivalent in the sense that the 
nonwasteful allocations of the private goods economy are in one-to-one correspondence with the feasible allocations of the externalities economy. This equivalence is implicit in what follows.

We now describe an allocation mechanism for the private goods economy. We consider a general description of the workings of a marketplace. Fix the number of players at $n$. Each player chooses an action $a_{i}$ from an action set $A_{i}, i=1, \ldots, n$. Let a denote the vector of actions. $A$ mechanism for our economy is a collection of action sets and outcome functions $x(a)$ and $y(a)$ which map the vector of actions into the space of feasible allocations. We assume there is a class of allowable payoffs $U_{i}$. Let $u=\left(u_{1}, \ldots, u_{n}\right) \in U=\left(U_{1} \times \ldots \times U_{n}\right)$. Let $N(u)$ denote the Nash equilibrium correspondence given a mechanism.

We will find it convenient to consider an alternative mechanism with action sets for each player given by $U$. The interpretation here is that each player reports the utility functions of all players in the economy. Let $t_{i} \in U$ (the type of player $i$ ) denote the vector of utility functions reported by player $i$ so that $t_{i j} \in U_{j}$ denotes $i$ 's report of $j$ 's utility function. Let $t$ denote the vector of types reported by all players. A revelation mechanism is a collection of type sets and allocation functions $\mathrm{x}^{\mathrm{r}}(\mathrm{t})$ and $\mathrm{y}^{\mathrm{r}}(\mathrm{t})$ which map reported types into the space of feasible allocations.

We now show that the equilibrium outcomes of any mechanism can be implemented as equilibrium outcomes of a revelation mechanism. Let $\psi$ denote a selection from the Nash equilibrium correspondence, $N(u)$, of an arbitrary mechanism. Define the outcome function $x^{r}(t)$ in the revelation mechanism by $x^{\mathrm{r}}(\mathrm{t})=\mathrm{x}\left(\psi_{1}\left(\mathrm{t}_{1}\right), \psi_{2}\left(\mathrm{t}_{2}\right), \ldots, \psi_{\mathrm{n}}\left(\mathrm{t}_{\mathrm{n}}\right)\right)$, and define $\mathrm{y}^{\mathrm{r}}(\mathrm{t})$ similarly. Note that in this formulation, the action chosen for player $i$ is the equilibrium action for the environment in which he or she claims to be playing. Because the vector of actions implied by $\psi$ constitutes an equilibrium for the original mechanism, it follows that truth-telling is also an equilibrium of the revelation mechanism and yields the same outcomes. We have proved the following theorem. 
Theorem 1 (Revelation principle): Suppose the Nash correspondence for some mechanism is nonempty for all $u \in U$. Then there is a revelation mechanism for which truth-telling is an equilibrium yielding the same outcomes.

We therefore restrict attention to revelation mechanisms. Exactly the same logic applies even with private information. In this case, a revelation mechanism yields the same outcomes as the Bayesian Nash correspondence of an arbitrary mechanism.

Note that the revelation principle contains two conclusions. First, it follows that one only need consider games in which the strategy space is given by vectors of reported utility functions. Second, it allows attention to be restricted to the truth-telling equilibria of the revelation mechanism. In some of the results that follow, we will only use the first of these two properties. So, in some cases at least, it is not necessary to construct the revelation game to check whether our axioms for decentralized mechanisms are satisfied.

The space of possible utility functions we consider in the revelation mechanism is $U_{i}=$ \{utility functions over smoke rights on $[0, Q]$ which are nondecreasing, with $\left.u_{i}(0)=0\right\}$. Associated with a revelation mechanism for our economy are outcome functions $x(t)$ and $y(t)$ that satisfy feasibility. For convenience let $m_{i}$ denote the consumption of the numeraire consumption good by consumer $i$ and let $q$ denote the amount of smoke produced. Then the outcome functions must satisfy

$$
\sum_{i} m_{i}(t) \leq \sum_{i} \bar{m}_{i}+R(q(t))
$$

and

$$
\sum_{i=1}^{n} x_{j}^{i}(t)=\bar{q}_{j}-q(t)
$$

$$
(\mathrm{j}=1, \ldots, \mathrm{n})
$$


for all $t \in U^{n}$, where $\bar{m}_{i}$ and $\bar{q}_{j}$ denote the endowments of the consumption good and smoke rights, respectively.

The payoffs in the revelation mechanism are then given by

$$
\left.\left.\mathrm{V}_{\mathrm{i}}(\hat{\mathrm{t}})=\mathrm{m}_{\mathrm{i}} \hat{\mathrm{t}}\right)+\mathrm{u}_{\mathrm{i}}\left(\mathrm{x}_{\mathrm{i}}^{\mathrm{i}} \hat{\mathrm{t}}\right)\right)
$$

for all $\hat{t} \in U^{n}$. For notational convenience, let $q_{i}=x_{i}^{i}$.

We can define a sequence of mechanisms as the population size $n$ changes. Note, of course, that the underlying commodity space and the spaces over which the outcome functions are defined also change. As we change the population size, we also allow the utility functions to change. We denote the utility function of consumer $i$ by $u_{i}\left(q_{i} ; n\right)$. We now prove that under a set of axioms, the equilibrium output of the revelation mechanisms converges to zero. Suppose, therefore, that the sequence of mechanisms satisfies these axioms:

Axiom A1 (Voluntary trade): For all $n$, for all $t \in U^{n}$, and for all $i=1, \ldots, n$,

$$
m_{i}(t, n)+t_{i i}\left(q_{i}(t, n) ; n\right) \geq \bar{m}_{i}+t_{i i}\left(\bar{q}_{i j} ; n\right)
$$

Axiom A2 (Continuity): For all $\delta>0$, there exists $\epsilon>0$ such that for all $\mathrm{n}$, for all $\mathrm{i}$ $=1, \ldots, \mathrm{n}$, for all $\mathrm{t} \in \mathrm{U}^{\mathrm{n}}$,

$$
\left|\mathrm{q}(\mathrm{t}, \mathrm{n})-\mathrm{q}\left(\mathrm{t}_{-\mathrm{i}}, \hat{\mathrm{t}}_{\mathrm{i}}, \mathrm{n}\right)\right|<\delta
$$

if

$$
\left|t_{i j}(x)-\hat{t}_{i j}(x)\right|<\epsilon
$$

for all $x \in[0, Q]$, for all $j=1, \ldots, n$. 
Axiom A1 is one way to represent the idea that every consumer has a right not to be affected by smoke unless he or she consents. This condition is stronger than the standard voluntary participation or individual rationality constraint familiar from the mechanism design literature. We require the outcome of a mechanism to make each individual at least as well off, when welfare is calculated with the reported utility function, as he or she would be without any trade at all. This axiom reduces to the standard individual rationality constraint in dominant strategy mechanisms.

Axiom A2 requires that no mechanism punish small deviations from truth-telling too severely. For example, mechanisms that simply impose efficient allocations if all reports agree and prescribe severe penalties for deviation are disallowed. One such mechanism gives each consumer his or her endowment if there is any disagreement among consumers about reported utility functions. If all consumers agree in their reports, the mechanism computes the Lindahl equilibrium for such an economy and gives each consumer the associated allocations. Clearly, truth-telling is a Nash equilibrium for such a mechanism. Although this mechanism is extremely discontinuous, it is possible to construct similar mechanisms that are continuous, but which punish deviations severely enough. A key feature of Axiom A2 is that it requires mechanisms to be uniformly continuous across the sequence of economies. Thus, the power of any individual to affect aggregate outcomes by small deviations is limited uniformly across the sequence of economies.

An alternative (and stronger) condition would require a small change in any consumer's report to have a correspondingly small effect on the allocations received by every other consumer. This condition might be more suitable for environments where the notion of an aggregate outcome is more difficult to define.

Mechanisms satisfying Axioms $A 1$ and $A 2$ seem to us to capture two key features of market mechanisms. Hence, we say that a sequence of mechanisms satisfying $\mathrm{A} 1$ and $\mathrm{A} 2$ is decentralized. 
Theorem 2 (Decentralized truth-telling mechanisms yield zero output in the limit): Consider a sequence of utility functions $u_{1}(1) ; u_{1}(2), u_{2}(2) ; u_{1}(3), u_{2}(3), u_{3}(3) ; \ldots$ Suppose the revenue function $R(q)$ is bounded above by $K<\infty$. Suppose truth-telling is an equilibrium. Denote the equilibrium output level by $q^{\mathrm{n}}=q(u(n), n)$. If $A 1$ and $A 2$ are satisfied, then $\lim _{\mathrm{n} \rightarrow \infty} q^{\mathrm{n}}=0$.

Proof: The argument is by contradiction. Suppose that $\lim _{n \rightarrow \infty} q^{n} \neq 0$. Choose subsequences if necessary so that $\lim _{k \rightarrow \infty} q^{n_{k}}=d>0$. In what follows, we drop the subscript $k$ for notational convenience. Since R(q) is bounded, using (3.1) we have that

$$
\sum_{i} m_{i}(u, n) \leq \sum_{i} \bar{m}_{i}+K
$$

From equation (3.2), using $q(u, n) \geq 0$ we get that $q_{i}(u, n) \leq \bar{q}_{i}$ for all $i$. Hence, from Axiom $A 1$ we have that $m_{i}(u, n) \geq \bar{m}_{i}$ for all $n$ and for all $i$. With (3.3), this implies that there is some sequence $i_{1}, i_{2}, \ldots$ such that

$$
\lim _{n \rightarrow \infty}\left[m_{i_{n}}(u, n)-\bar{m}_{i_{n}}\right]=0 .
$$

Without loss of generality, we assume that $i_{n}=1$ for all $n$. Using Axiom $A 1$ and (3.4), we have

$$
\lim _{n \rightarrow \infty}\left[u_{1}\left(q_{1}(u, n) ; n\right)-u_{1}\left(q_{1} ; n\right)\right]=0 .
$$

Consider an alternative strategy for agent 1 , denoted by $\hat{t}_{1}$, of reporting the same utility functions of the other players as under strategy $u$ and

$$
\hat{t}_{11}(x ; n)=u_{1}(x ; n)+\frac{\epsilon}{Q} x,
$$

where $\epsilon$ is a small positive number determined below. 
The payoffs for agent 1 are then given by

$$
V_{1}\left(u_{-1}, \hat{t}_{1} ; n\right)=m_{1}\left(u_{-1}, \hat{t}_{1}, n\right)+u_{1}\left(q_{1}\left(u_{-1}, \hat{t}_{1}, n\right) ; n\right)
$$

From Axiom A1 we have that

$$
m_{1}\left(u_{-1}, \hat{t}_{1}, n\right)+\hat{t}_{11}\left(q_{1}\left(u_{-1}, \hat{t}_{1}, n\right) ; n\right) \geq \bar{m}_{1}+\hat{t}_{11}\left(\bar{q}_{1}\right)
$$

Using (3.8), we get the utility difference between the alternative strategy and the equilibrium strategy:

$$
\begin{aligned}
& \Delta_{\mathrm{n}}=\mathrm{v}_{1}\left(\mathrm{u}_{-1} ; \hat{\mathrm{t}}_{1} ; \mathrm{n}\right)-\mathrm{v}_{1}(\mathrm{t} ; \mathrm{n}) \geq\left[\mathrm{u}_{1}\left(\mathrm{q}_{1}(\hat{\mathrm{t}}, \mathrm{n}) ; \mathrm{n}\right)-\hat{\mathrm{t}}_{11}\left(\mathrm{q}_{1}(\hat{\mathrm{t}}, \mathrm{n}) ; \mathrm{n}\right)\right] \\
& \quad+\left[\overline{\mathrm{m}}_{1}+\hat{\mathrm{t}}_{11}\left(\overline{\mathrm{q}}_{1}\right)\right]-\left[\mathrm{m}_{1}(\mathrm{t})+\mathrm{u}_{1}\left(\mathrm{q}_{1}(\mathrm{u}, \mathrm{n}) ; \mathrm{n}\right)\right]
\end{aligned}
$$

where $q_{1}(\hat{t}, n)=q_{1}\left(t_{-1}, \hat{t}_{1}, n\right)$

Adding and subtracting $\mathrm{u}_{1}\left(\overline{\mathrm{q}}_{1}\right)$ to and from the right side of (3.9), after rearranging we get

$$
\begin{aligned}
\Delta_{\mathrm{n}} \geq\left[\mathrm{u}_{1}\left(\mathrm{q}_{1}(\hat{\mathrm{t}}, \mathrm{n}) ; \mathrm{n}\right)-\mathrm{u}_{1}\left(\overline{\mathrm{q}}_{1} ; \mathrm{n}\right)\right] & -\left[\hat{\mathrm{t}}_{11}\left(\mathrm{q}_{1}(\hat{\mathrm{t}}, \mathrm{n}), \mathrm{n}\right)-\hat{\mathrm{t}}_{11}\left(\overline{\mathrm{q}}_{1} ; \mathrm{n}\right)\right] \\
& +\left[\overline{\mathrm{m}}_{1}+\mathrm{u}_{1}\left(\overline{\mathrm{q}}_{1}\right)-\mathrm{m}_{1}(\mathrm{t})-\mathrm{u}_{\mathbf{i}}\left(\mathrm{q}_{1}(\mathrm{u}, \mathrm{n}) ; \mathrm{n}\right)\right] .
\end{aligned}
$$

From (3.4) and (3.5) we have that the last term (in brackets) goes to zero. Consider the remaining terms. These are given from the definition of $\hat{t}_{11}$ in (3.6) by

$$
\frac{\epsilon}{\mathrm{Q}}\left[\overline{\mathrm{q}}_{1}-\mathrm{q}_{1}(\hat{\mathrm{t}}, \mathrm{n})\right]
$$

Feasibility requires that $\left.\bar{q}_{1}-q_{1}(\hat{t}, n) \geq q \hat{(t}, n\right)$. Recall that $\lim _{n \rightarrow \infty} q(u, n)=d$. Choose $\delta$ so that $d-\delta>0$. From Axiom A2 we have that there exists $\epsilon>0$ such that 


$$
\left|q(u, n)-q\left(u_{-1}, \hat{t}_{1}, n\right)\right|<\delta
$$

if $\left|\hat{t}_{1}-t_{1}\right|<\epsilon$.

Therefore, given $\delta$, the deviation $\hat{\mathrm{t}}_{1}$ can be chosen so that $\mathrm{q}(\hat{\mathrm{t}}, \mathrm{n})>\mathrm{q}(\mathrm{t}, \mathrm{n})-\delta$. Since $q(u, n)$ converges to a positive constant $d$, we have that

$$
\lim _{n \rightarrow \infty} \Delta_{n} \geq \frac{\epsilon}{Q}(d-\delta)>0 .
$$

Hence, the difference in utilities is strictly positive for large enough $n$.

The result that $\mathrm{q}(\mathrm{n}) \rightarrow 0$ does not necessarily imply that the outcome is inefficient. In fact, it is easy to construct sequences of economies where this is the only efficient outcome. A simple example is the case where $u_{i}(n)$ is the same (and nonzero) for all $i$ and $n$.

Thus, the importance of the theorem lies in the fact that the result holds for a large class of economies in which the efficient outcomes are bounded away from zero. The examples of Section 2 belong to this class. Another example is given by $u_{i}(n)=(1 / n) u_{1}(1)$. This gives rise to a sequence of economies in which the Lindahl equilibrium is independent of $n$ (and positive in cases of interest). Other examples of this type give rise to sequences of economies in which the Lindahl equilibrium quantity is bounded away from zero, though dependent on $\mathrm{n}$. The theorem shows that with decentralized mechanisms the equilibrium level of output converges to zero even in this class of economies.

Theorem 2 shows that the truth-telling equilibria of decentralized mechanisms yield extremely inefficient outcomes for a large class of economies. In many cases of interest, however, our axioms are often difficult to verify for games where truth-telling is not an equilibrium. We now 
show that, in such cases, if the mechanisms satisfy a monotonicity axiom, all equilibria yield zero output in the limit.

Axiom A3 (Monotonicity): For all $n$, for all $t \in U^{n}$, for all $i=1, \ldots, n$, for all $\hat{t}_{i} \in$ U such that $\hat{t}_{\mathrm{ii}}(x) \geq \mathrm{t}_{\mathrm{ii}}(\mathrm{x})$ for all $x \in[0, \mathrm{Q}], \mathrm{q}_{\mathrm{i}}\left(\mathrm{t}_{-\mathrm{i}}, \hat{\mathrm{t}}_{\mathrm{i}}, \mathrm{n}\right) \geq \mathrm{q}_{\mathrm{i}}(\mathrm{t}, \mathrm{n})$.

The monotonicity axiom requires that if any person claims to value his or her smoke rights more, the mechanism should give that person more smoke rights.

Theorem 3 (Decentralized, monotone mechanisms yield zero output in the limit): Consider a sequence of utility functions $u_{1}(1) ; u_{1}(2), u_{2}(2) ; u_{1}(3), u_{2}(3), u_{3}(3) ; \ldots$. Suppose the revenue function $R(q)$ is bounded by $K<B$. Let $t(n)$ denote a sequence of equilibria for a sequence of revelation mechanisms, and denote the equilibrium output level by $q^{\mathrm{n}}=q(t(n), n)$. If $A 1, A 2$, and $A 3$ are satisfied, then $\lim _{\mathrm{n} \rightarrow \infty} q^{\mathrm{n}}=0$.

Proof: The argument is by contradiction. Dropping subscripts on subsequences, we have that there is some $d>0$ such that $\lim _{n \rightarrow \infty} q^{n}=d$. Using the boundedness of the revenue function, we have that there is some sequence of individuals $i_{1}, i_{2}, i_{3}, \ldots$ such that

$$
\lim _{n \rightarrow \infty}\left[m_{i_{n}}(t(n), n)-\bar{m}_{i_{n}}\right]=0
$$

Without loss of generality, let $\dot{i}_{\mathbf{n}}=1$ for all $\mathrm{n}$. Consider an alternative strategy for person 1 , denoted by $\hat{t}_{1}$, of reporting the same utility functions of the other players as under $t_{1}(n)$ and

$$
\hat{\mathrm{t}}_{11}(\mathrm{x} ; \mathrm{n})=\mathrm{t}_{11}(\mathrm{x} ; \mathrm{n})+\frac{\epsilon}{\mathrm{Q}} \mathrm{x}
$$


where $\epsilon$ is a number determined below. The difference in payoffs between the alternative strategy and the equilibrium strategy is given by

$$
\begin{aligned}
\Delta_{n} & =V_{1}\left(\hat{t}_{1}(n), t_{-1}(n) ; n\right)-v_{1}(t(n) ; n) \\
& =m_{1}(\hat{t}(n), n)+u_{1}\left\{q_{1}(\hat{t}(n), n) ; n\right\}-\left[m_{1}(t(n), n)+u_{1}\left\{q_{1}(t(n), n) ; n\right\}\right],
\end{aligned}
$$

where $\left.\hat{t}(n)=\hat{t}_{1}(n), t_{-1}(n)\right)$. Using monotonicity and the fact that $u_{1}$ is nondecreasing, we have that

$$
\Delta_{n} \geq m_{1}(\hat{t}(n), n)-m_{1}(t(n), n)
$$

Using Axiom A1 and (3.12), we have that

$$
\mathrm{m}_{1}(\hat{\mathfrak{t}}(\mathrm{n}), \mathrm{n})-\overline{\mathrm{m}}_{1} \geq \mathrm{t}_{11}\left(\overline{\mathrm{q}}_{1} ; \mathrm{n}\right)-\mathrm{t}_{11}\left(\mathrm{q}_{1}(\hat{\mathrm{t}}(\mathrm{n}), \mathrm{n}) ; \mathrm{n}\right)+\frac{\epsilon}{\mathrm{Q}}\left\{\overline{\mathrm{q}}_{1}-\mathrm{q}_{1}(\hat{\mathrm{t}}(\mathrm{n}), \mathrm{n})\right\}
$$

From (3.14) and (3.15), using the fact that $t_{11}$ is nondecreasing, we have that

$$
\Delta_{\mathrm{n}} \geq \frac{\epsilon}{\mathrm{Q}}\left\{\overline{\mathrm{q}}_{1}-\mathrm{q}_{1}(\hat{\mathrm{t}}(\mathrm{n}), \mathrm{n})\right\}-\mathrm{m}_{1}(\mathrm{t}(\mathrm{n}), \mathrm{n})+\overline{\mathrm{m}}_{1}
$$

The last two terms in (3.16) converge to zero from (3.11). Using Axiom A2 and choosing $\delta$ so that $\mathrm{d}-\delta>0$, we get that the difference in utilities is strictly positive for large enough $\mathrm{n}$. We have the desired contradiction.

One objection to Theorems 2 and 3 is that our proof strategy requires deviations which may be large relative to an individual's true utility function. In cases of interest, $u_{i}(n)$ converges to zero as $\mathrm{n} \rightarrow \infty$, but the deviations we use do not converge to zero. In other words, the space of utility functions from which individuals make their reports is large relative to the space of utility functions for which efficient outcomes have output bounded away from zero. To address this 
objection, we restrict the domain of the revelation mechanisms. Let $U_{B}$ be the set of utility functions over smoke rights on $[0, Q]$ which are nondecreasing, with $u_{i}(0)=0$ and which satisfy the condition that, for all $x, \hat{x} \in[0, Q],|u(x)-u(\hat{x})| \leq B / n|x-\hat{x}|$.

The voluntary trade axiom is unchanged. We strengthen the continuity axiom by imposing a Lipschitz condition on how the allocation of smoke rights changes with a change in a person's reported type.

Axiom A2' (Lipschitz continuity): For all $n$, for all $i=1, \ldots, n$, and for all $t, \hat{t} \in U_{B}^{n}$, there exists $A>0$ such that

$$
\left|q_{i}(t, n)-q_{i}\left(t_{-1}, \hat{t}_{i}, n\right)\right| \leq A\left\|t_{i}-\hat{t}_{i}\right\|
$$

where $\|\cdot\|$ is the sup-norm.

We have imposed the Lipschitz continuity requirement directly on each person's allocation of smoke rights. This condition is clearly equivalent to a requirement that output be Lipschitzcontinuous in the reported type combined with a nonwastefulness condition. We now show that if a sequence of mechanisms satisfies Axioms $A 1$ and $A 2 '$, then in the limit $R(q) \geq B q$.

Theorem 4 (Decentralized mechanisms yield inefficient outcomes): Consider a sequence of utility functions $u_{1}(1) ; u_{1}(2), u_{2}(2) ; \ldots$. Suppose the domain of the revelation mechanism is $U_{\mathrm{B}}^{\mathrm{m}}$. Let $t(n)$ denote an equilibrium of the revelation mechanism. Suppose $R(q)$ is bounded. Then

$$
\lim _{n \rightarrow \infty} \sup \{R[q(t(n), n)-B q(t(n), n)]\} \geq 0
$$

Remark: To understand this result, suppose there is some number $\mathrm{K}$ such that $\mathrm{R}(\mathrm{q}) \leq$ Kq. (That is, in terms of Examples 1 and 2, suppose there is a finite reservation price for the 
demand curve.) Suppose now that $\mathrm{B}>\mathrm{K}$. Then $\mathrm{q}$ converges to zero. An alternative way of stating this result is that if, for some profile of utility functions in $\mathrm{U}_{\mathrm{B}}^{\mathrm{n}}$, efficiency requires zero output, then no matter what the actual preference profile is, output under decentralized mechanisms converges to zero.

Proof: The argument is by contradiction. Let $\mathrm{n}_{\mathrm{k}}$ denote a subsequence satisfying

$$
\lim _{k \rightarrow \infty}\left[R\left\{q\left(t\left(n_{k}\right), n_{k}\right)-B q\left(t\left(n_{k}\right), n_{k}\right)\right\}\right]=2 d<0 .
$$

Without loss of generality, we define the subsequence so that the term in the brackets in (3.17) is less than or equal to $d$ for all $k$. For notational convenience, we drop the subscript on the subsequence $i_{n}$ in what follows. Choose $i_{n}$ so that

$$
\mathrm{m}_{\mathrm{i}_{\mathrm{n}}}(\mathrm{t}(\mathrm{n}), \mathrm{n})-\overline{\mathrm{m}}_{\mathrm{i}_{\mathbf{n}}}(\mathrm{n})=\min _{\mathbf{i}}\left[\mathrm{m}_{\mathbf{i}}(\mathrm{t}(\mathrm{n}), \mathrm{n})-\overline{\mathrm{m}}_{\mathrm{i}}(\mathrm{n})\right] .
$$

With (3.1) it is easy to show that (3.17) implies that

$$
n\left[m_{i_{n}}(t(n), n)-\bar{m}_{i_{n}}(n)\right] \leq B q(t(n), n)+d
$$

for all $n$.

Without loss of generality, let $i_{n}=1$ for all $n$. Consider the following deviation denoted by $\hat{t}_{1}$ for person 1 . Let the report of the utility function of the other players be unchanged, and let

$$
\hat{t}_{11}(x ; n)=\frac{B}{n} x .
$$

Using A1, we then have that

$$
\hat{\mathrm{m}}_{1}(\mathrm{n}) \geq \overline{\mathrm{m}}_{1}(\mathrm{n})+\frac{\mathrm{B}}{\mathrm{n}}\left[\overline{\mathrm{q}}_{1}(\mathrm{n})-\mathrm{q}_{1}(\mathrm{n})\right]
$$

where $\left.\hat{m}_{1}(n)=m_{1} \hat{t}_{1}(n), t_{-1}(n), n\right)$ and $\hat{q}_{1}(n)$ is similarly defined. 
From (3.18), (3.20), and the fact that $\mathrm{q}_{1}(\mathrm{t}(\mathrm{n}), \mathrm{n}) \leq \overline{\mathrm{q}}_{1}(\mathrm{n})-\mathrm{q}_{1}(\mathrm{t}(\mathrm{n}), \mathrm{n})$, the difference in utilities between the alternative strategy and the equilibrium strategy satisfies

$$
n \Delta_{n} \geq B\left(q_{1}(n)-\hat{q}_{1}(n)\right)-d+n u_{1}\left(\hat{q}_{1}(n) ; n\right)-n_{1}\left(q_{1}(n) ; n\right)
$$

where $\mathrm{q}_{1}(n)=\mathrm{q}_{1}(t(n), n)$. Now, if $\hat{\mathrm{q}}_{1}(\mathrm{n}) \leq \mathrm{q}_{1}(\mathrm{n})$ for some $n$, then $\mathrm{u}_{1}\left(\hat{\mathrm{q}}_{1}(\mathrm{n}) ; n\right)-\mathrm{u}_{1}\left(\mathrm{q}_{1}(\mathrm{n}) ; n\right) \geq$ $-B / n\left(\hat{q}_{1}(n)-q_{1}(n)\right)$ and, since $d<0$, we have a contradiction. If $\hat{q}_{1}(n)>q_{1}(n)$, we can use Axiom $\mathrm{A}^{\prime}$ and the fact that $\mathrm{u}_{1}$ is nondecreasing in (3.21) to get

$$
\mathrm{n} \Delta_{\mathrm{n}} \geq \frac{-\mathrm{AB}^{2} \mathrm{Q}}{\mathrm{n}}-\mathrm{d}
$$

Recall that $d<0$. Therefore, $\mathrm{n}$ can be chosen sufficiently large so that the right side of (3.22) is strictly positive, and we have a contradiction.

\section{Monopoly Power and the Free-Rider Problem}

We have transformed our environment into a private ownership economy and shown that decentralized mechanisms lead, in general, to extremely inefficient outcomes with a large enough population. In this formulation, monopoly power in the ownership of smoke rights plays a central role in generating inefficient outcomes. Alternatively, we could have set up a mechanism design problem in an environment with externalities. In this case, the preferences of the agents over smoke are given by

$$
\mathrm{m}_{\mathrm{i}}-\mathrm{v}_{\mathrm{i}}(\mathrm{q})
$$

where $q$ is the amount of smoke produced in the town and $v_{i}$ is a nondecreasing function on $[0, Q]$. A revelation mechanism in this economy is defined analogously to the setup in the privatized economy as a collection of type sets for agents and outcome functions $m(t)$, $q(t)$ which specify 
consumption vectors of the numeraire good and production of smoke, respectively. Feasibility requires that a mechanism satisfy (3.1). Consider a sequence of mechanisms as the population size, n, changes. Suppose that the sequence of mechanisms satisfies these two axioms:

Axiom $A 1^{\prime}$ (Veto power): For all $n$ and for all $t \in U^{n}$, $m_{i}(t, n)-t_{i}(q(t, n) ; n) \geq \bar{m}_{i}-t_{i}(0 ; n)$.

Axiom A2" (Continuity): For all $\delta>0$, there exists $\epsilon>0$ such that for all $\mathrm{n}$, for all $\mathrm{i}=1, \ldots, \mathrm{n}$, and for all $\mathrm{t} \in \mathrm{U}^{\mathrm{n}}$,

$$
\left|\mathrm{q}(\mathrm{t}, \mathrm{n})-\mathrm{q}\left(\mathrm{t}_{-\mathrm{i}}, \hat{\mathrm{t}}_{\mathrm{i}}, \mathrm{n}\right)\right|<\delta
$$

if

$$
\left|t_{i j}(x)-\hat{t}_{i j}(x)\right|<\epsilon
$$

for all $x \in[0, Q]$ and for all $j=1, \ldots, n$.

The monotonicity and Lipschitz continuity axioms are defined analogously. The veto power or individual rationality condition, Axiom $\mathrm{A}^{\prime}$, makes more explicit that the voluntary trade axiom, A1, is a description of the legal environment underlying the privatized economy. The obvious question of alternative legal environments is addressed in Section 5 .

It is easy to prove, along the lines of Theorems 2 and 3 , that if the revenue function is bounded, then the equilibrium output of smoke converges to zero. It is also easy to prove, along the lines of Theorem 4, that, with Lipschitz continuity, outcomes are generally inefficient and, under plausible conditions, equilibrium output converges to zero. This formulation of the problem shows that our result of extreme inefficiency does not depend on the particular way that we have privatized 
the public goods economy. In fact, the privatized public goods economy formulation is in some ways more general than the public goods formulation.

To see this, consider the following privatized economy. Let the endowment of smoke rights for each agent be the same, say, $\bar{q}$. We restrict attention to mechanisms that allocate positive consumption rights at location $i$ only to consumer $i$. That is, let $x_{j}^{i}=0$ if $i \neq j$. Define $u_{i}\left(x_{i}^{i}\right) \equiv$ $-v_{\mathbf{i}}\left(\bar{q}-x_{\mathbf{i}}^{\mathbf{i}}\right)$. Clearly, the theorems continue to apply.

In the public goods formulation, the extreme inefficiency of outcomes results from the free-rider problem. In the privatized economy, complementarities create monopoly power and the resulting allocations are inefficient. In this sense, the free-rider problem is a problem of monopoly power.

\section{Comments, Examples, and Extensions}

(vi) It is clear from the proofs of Theorems 2 and 3 that Axiom A2 can be weakened considerably. In particular, all that is used in the proofs is that if $\mathrm{q}(\mathrm{t}(\mathrm{x}))$ is bounded away from zero, then $\mathrm{q}(\mathrm{t}(\mathrm{x})+\alpha \mathrm{x})$ is also bounded away from zero for all sufficiently small $\alpha$. This suggests the following alternative for Axiom A2:

Axiom A4 (Limited responsiveness): For all $\delta>0$, there exist $\epsilon_{1}>0$ and $\epsilon_{2}>0$ such that for all $\mathrm{n}$, if $\mathrm{q}(\mathrm{t}, \mathrm{n})>\delta$, then for all $\hat{\mathrm{t}}$ such that $\|\hat{\mathrm{t}}-\mathrm{t}\|<\epsilon_{1}, \mathrm{q}(\hat{\mathrm{t}}, \mathrm{n})>\epsilon_{2}$, where $\|\cdot\|$ is the sup-norm.

Clearly, Axiom A2 implies Axiom A4. It is easy to see that Theorems 2 and 3 still hold with this weaker axiom.

(vii) Recall that Theorems 3 and 4 do not require the assumption of truth-telling. Because truth-telling is not required, it is possible to directly verify the axioms in some specific applications 
without first calculating the equilibrium correspondence and then constructing the resulting revelation mechanism. We will use this fact repeatedly in what follows.

(viii) As an example of the types of games covered by Theorems 3 and 4, suppose that each individual has the same allocation of rights and that, for a sequence of mechanisms, output is given by a continuous function of the sum of the reported utilities of the agents: $q=$ $\mathrm{g}\left(\sum_{\mathrm{i}=1}^{\mathrm{n}} \mathrm{t}_{\mathrm{ii}}(\overline{\mathrm{q}}-\mathrm{q})\right)$, where $\mathrm{g}: \mathrm{U} \rightarrow \mathrm{R}$ is monotone-decreasing and uniformly continuous (with respect to the sup-norm topology) on U. Then Axioms A2 and A3 are automatically satisfied. It follows that Theorem 3 applies as long as Axiom A1 is satisfied. Alternatively, suppose that g satisfies a Lipschitz condition. Then Theorem 4 applies.

A specific example illustrates the usefulness of this formulation. Consider a mechanism in which each agent announces a vector of utility functions, $t_{\mathrm{i}}$. Output is determined by equating $R(q)$ to $\sum_{i=1}^{n} t_{i i}(\bar{q}-q)$, and each individual receives a payment equal to $t_{i i}$ at the $q$ given above. Under this mechanism, Axioms $\mathrm{A} 2$ and $\mathrm{A} 3$ are clearly satisfied for a large class of revenue functions $\mathrm{R}$, and Axiom $\mathrm{A} 2^{\prime}$ is satisfied for another class. Clearly, since Axiom $\mathrm{A} 1$ is satisfied, Theorems 3 and 4 hold.

Alternatively, this construction can be interpreted as a nonlinear pricing game in which each agent chooses a payment schedule $\mathrm{p}_{\mathfrak{i}}(q)$ as a function of the level of pollution. Let $q(t)$ be chosen by equating $\mathrm{R}(\mathrm{q}) / \mathrm{q}$ to $\sum_{\mathrm{i}=1}^{\mathrm{n}} \mathrm{p}_{\mathrm{i}}(\mathrm{q})$. Competitive firms produce output and make the required payments to individuals as in the examples of Section 2. As long as $R(q) / q$ is continuous, both Axioms A1 and A2 are satisfied. Moreover, as long as R(q)/q is continuous in a neighborhood of $q=0$, both Axioms A1 and A4 are satisfied (even if $R(q)$ is not continuous everywhere). 
(ix) Consider a slight variation on this pricing game. Each individual announces a vector of utilities $t_{i i}(q)$ which are differentiable. Let $q(t)$ be given by setting $R(q) / q=\sum_{i=1}^{n} t_{i i}^{\prime}(q)$. Suppose $R$ is such that the resulting value of $q$ is monotone-decreasing in $t_{i i}^{\prime}$. Payments are given by $t_{\mathrm{ii}}^{\prime}(q) q$. Note that, as written, this mechanism satisfies neither Axiom A2 nor Axiom A4 in general, since small changes in the reported utilities can be associated with large changes in the associated marginal utilities. It follows that small changes in the reported utilities can be associated with both large changes in $\mathrm{q}$ (so that Axiom $\mathrm{A} 2$ is not satisfied) and large changes in $\mathrm{q}$ which result in output levels arbitrarily close to zero (so that Axiom A2" is not satisfied). Nevertheless, the proof of Theorem 3 holds for this example without any change whatever.

Thus Axiom A2 can be relaxed even further than in Axiom A4. In particular, the proof requires only that Axiom $A 2$ hold for deviations of the form $\hat{t}(x)=t(x)+\alpha x$. Therefore, although either Axiom A2 or Axiom A4 is sufficient for the result, neither is necessary.

(x) Another way to extend Theorem 3 is to relax the requirement that the mechanism be defined for all increasing utility functions. An obvious and relevant alternative is to restrict $U$ to be the class of all increasing and concave utility functions on $[0, \mathrm{Q}]$. Indeed, the proof of Theorem 3 still holds for any class $U$ with the property that if $t \in U$, then $t(x)+\alpha x \in U$ provided Axioms A1, A2 (or A4), and A3 hold in U. It follows that the example presented in (ix) satisfies this alternative formulation of the result as long as attention is restricted to increasing, differentiable, and concave utility functions.

Another example in this vein is the pricing game discussed in Section 2, which corresponds to a special case of the games discussed in (viii) and (ix) with U given by the class of linear utilities. 
(xi) The conclusions of the theorems do not hold for some mechanisms. We discussed one such example before the statement of the theorems. As another example, consider an extension of the bargaining game to our environment. Nature moves first, choosing a dictator. The dictator's strategy is to select an allocation for each agent in the economy. The strategies of the other players are limited to either agreeing or disagreeing. All players move simultaneously. If all players other than the dictator agree, the outcome is the allocation named by the dictator. If any player disagrees, the outcome is for each player to consume his or her endowment. This game clearly has one equilibrium that is efficient (among the players of the game). It follows that for some sequences of utility profiles, the quantity of output in this equilibrium is uniformly bounded away from zero. (This game has other equilibria as well. In particular, zero output is always an equilibrium of the game as formulated.) It can be verified that Axiom A1 is not satisfied for this example.

This example suggests other possibilities that could be explored. In particular, extending the formulation to sequential move games (more in the spirit of Rubinstein (1982)) provides other examples where the conclusion of Theorem 2 does not hold.

(xii) We turn now to the particular normalization of demand we have chosen. We have kept demand for the final good unaffected as the population size $\mathrm{n}$ changes. Suppose instead that demand for the final good grows at rate $\mathrm{n}$. We show that the ratio of equilibrium output to the efficient level of output goes to zero as $n$ gets sufficiently large. Thus, although output itself need not go to zero, it is arbitrarily far from the efficient level.

Suppose, therefore, that $R_{n}(q)=n R(q)$, where $R(q)$ is bounded. Suppose as before that the revelation mechanism has an equilibrium. Consider the following transformed game. (We use a caret $\left({ }^{\wedge}\right)$ to denote the transformed game.) The strategy spaces are unaltered. The outcome functions for the transformed game are defined by 
and

$$
\hat{\mathrm{m}}_{\mathrm{i}}(\mathrm{t}, \mathrm{n})=\frac{\mathrm{m}_{\mathrm{i}}(\mathrm{t}, \mathrm{n})}{\mathrm{n}}
$$

$$
\hat{\mathrm{q}}(\mathrm{t}, \mathrm{n})=\frac{\mathrm{q}(\mathrm{t}, \mathrm{n})}{\mathrm{n}} \text {. }
$$

Payoffs are defined by $\hat{V}_{i}(\hat{m}, \hat{q})=\hat{m}+(1 / n) u_{i}(n \hat{q})$. If $\left(m^{n}, q^{n}\right)$ is an equilibrium outcome of the original game, then $\left(\hat{\mathrm{m}}^{\mathrm{n}}, \hat{\mathrm{q}}^{\mathrm{n}}\right)$ is an equilibrium outcome of the transformed game. From Theorem 2, it follows that for the transformed game, the equilibrium output level $\hat{q}$ converges to zero. Now, in general, the efficient level of output is uniformly bounded away from zero in the transformed environment. Hence, in general, the ratio of equilibrium output to the efficient level of output converges to zero in the original environment. Similar arguments apply for Theorem 4.

\section{The General Approach With Private Information}

The voluntary trade assumption of Section 3 is a very strong notion of property rights given our assumption of public information. Our goal in this section is to show that this assumption can be considerably weakened in environments with private information. We prove two results for the private information case that are analogues of Theorem 2 . We show that with either independently drawn utilities and a 'standard' individual rationality assumption or with a constant support assumption and ex post individual rationality, the equilibrium level of output converges to zero. Although we do not explore this here, presumably analogues of Theorems 3 and 4 also hold in these settings.

We will need some additional notation to develop the environment with private information. To simplify the presentation, we will make stronger probabilistic assumptions than are necessary. See the comments at the end of this section for more details on this. Let $U$ be the set of nondecreasing, continuous functions on $[0, Q]$ with $u(0)=0$. Equip $U$ with the sup-norm 
topology. The utility functions of the players of the game are random variables on $U^{n}$. Let $B^{n}$ be the Borel sigma algebra on $U^{\mathrm{n}}$ generated by the sup-norm topology. Let $\mu^{\mathrm{n}}$ denote a sequence of probability measures on $\left(\mathrm{U}^{\mathrm{n}}, \mathrm{B}^{\mathrm{n}}\right)$. Let $\mu_{\mathrm{i}}^{\mathrm{n}}$ denote the marginal probability measure for $\mu^{\mathrm{n}}$. For expositional reasons, we will assume that supp $\mu^{\mathbf{n}}=X_{i=1}^{n}$ supp $\mu_{i}^{\mathfrak{n}}$. As will become clear, this assumption can be relaxed to some extent.

An allocation mechanism for our private goods economy can be defined analogously to that in Section 3. As in that section, it is straightforward to establish the revelation principle. We will therefore restrict attention to revelation mechanisms. To simplify notation, we will suppress consumption of smoke rights at location $j$ for individual $i$ when $j \neq i$. A revelation mechanism for an economy with $\mathrm{n}$ agents is denoted by $\Gamma^{\mathrm{n}}$ and is a collection of $(2 n+1)$ measurable outcome functions given by $m_{i}: U^{\mathfrak{n}} \rightarrow \mathbf{R}_{+}, q_{i}: U^{n} \rightarrow \mathbf{R}_{+}, q: U^{n} \rightarrow \mathbf{R}_{+}$, where $m_{i}$ denotes consumption of the numeraire good by agent $i, q_{i}$ denotes consumption of smoke rights by agent $i$, and $q$ denotes output. We require that these outcome functions satisfy feasibility:

$$
\begin{aligned}
& \sum_{i} m_{i}(u) \leq \sum \bar{m}_{i}+R(q(u)) \\
& q_{i}(u) \leq \bar{q}_{i}-q(u), \quad i=1, \ldots, n, \\
& m_{i}(u) \geq \bar{m}_{i}, \quad i=1, \ldots, n,
\end{aligned}
$$

for all $\mathrm{u}$ in the support of $\mu^{\mathrm{n}}$, where $\overline{\mathrm{m}}_{\mathrm{i}}$ denotes agent i's endowment of the numeraire good.

For notational convenience, let $\Omega=\left(U^{1} \times U^{2} \times \ldots\right), \Im=\left(B^{1} \times B^{2} \times \ldots\right)$, and $P=$ $\left(\mu^{1} \times \mu^{2} \times \ldots\right)$ define the underlying probability space.

A Bayesian Nash equilibrium of $\Gamma^{\mathbf{n}}$ is a strategy profile consisting of $\mathbf{n}$ measurable functions denoted by $s_{i}$, each mapping $U$ to $U$ such that, for all $i$, for any measurable function, $\hat{s}_{i}$ : $\mathrm{U} \rightarrow \mathrm{U}$ 


$$
\begin{aligned}
& E\left[m_{i}(s(u))+u_{i}\left(q_{i}(s(u))\right) \mid u_{i}\right] \\
& \quad \geq E\left[m_{i}\left(s_{i}(u), s_{-i}(u)\right)+u_{i}\left(q_{i}\left(s_{i}(u), s_{-i}(u)\right)\right) \mid u_{i}\right] \text { a.s. }
\end{aligned}
$$

Note that since $\Omega$ is a complete, separable metric space, $(\Omega, \Im, p)$ is a regular probability space and the conditional expectations in (4.4) are well defined. (See Breiman (1968).)

Truth-telling is an equilibrium of the revelation mechanism if $s_{i}(u)=u$ for all $i$ is a Bayesian Nash equilibrium.

We now turn to the axioms that define decentralized mechanisms. We will start with the analogue of our voluntary trade axiom for mechanisms with no private information:

Axiom B1 (Interim voluntary trade): For all $\mathrm{n}$, for all $\mathrm{i}$, the revelation mechanism satisfies

$$
E\left[m_{i}(u)+u_{i}\left(q_{i}(u)\right) \mid u_{i}\right] \geq \bar{m}_{i}+u_{i}\left(\bar{q}_{i}\right) \quad \text { for all } u_{i} \in \operatorname{supp} \mu_{i}^{n} \text {. }
$$

This axiom is the standard individual rationality condition in the mechanism design literature. It says that if agent $\mathrm{i}$ believes that all other players are telling the truth, the agent can by telling the truth guarantee him- or herself a conditional expected utility at least as large as the utility of the agent's endowment. The axiom captures the idea that after an agent sees his or her draw of the utility function, the agent can leave with the endowment intact.

The analogue of the continuity axiom is

Axiom B2 (Continuity): For all $\epsilon>0$, there exists $\delta>0$, such that for all $\mathrm{n}$, for all $\mathrm{u}_{-\mathrm{i}} \in \mathrm{U}^{\mathrm{n}-1}$, for all $\mathrm{u}_{\mathrm{i}}, \hat{\mathrm{u}}_{\mathrm{i}} \in \mathrm{U}$,

$$
\left|q\left(u_{i}, u_{-i}\right)-q\left(\hat{u}_{i}, u_{-i}\right)\right|<\epsilon
$$


if

$$
\left\|u_{i}-\hat{u}_{i}\right\|<\delta
$$

for all $\mathrm{i}=1, \ldots, \mathrm{n}$, where $\|\cdot\|$ is the sup-norm.

As in Section 3, note that Axiom B2 requires uniform continuity of the outcome functions.

While our continuity axiom is essentially the same with and without private information, note that our individual rationality axiom is substantially weaker with private information. To see this, suppose the utility functions of all the players are perfectly correlated random variables. Then the utility function of any player is known if all the other players tell the truth about their utility functions. One can devise mechanisms in this case which ignore reports by a player of his or her own utility function and thus limit the monopoly power of any given player. Such mechanisms satisfy Axiom B1, but clearly will not satisfy the voluntary trade axiom, A1. Furthermore, recall that in the proofs of our earlier theorems, we constructed deviations that were possibly large relative to an individual's true utility function. In the private information case, any deviation must be credible; that is, it must be in the support of the domain of utility functions. Thus, we need to ensure that the support of the domain of utility functions does not shrink too rapidly with the number of players. In particular, we require that the revelation mechanism satisfies this axiom:

Axiom B3 (Support): For all $\delta_{1}, \delta_{2}>0$, there exist $\epsilon_{1}, \epsilon_{2}>0$ such that for all $\mathrm{n}$, for all $\mathrm{i}=1, \ldots, \mathrm{n}$, for all $u_{\mathrm{i}} \in \operatorname{supp} \mu_{\mathrm{i}}^{\mathrm{n}}$ such that

$$
u_{i}(\bar{q})-u_{i}\left(\bar{q}-\delta_{1}\right) \leq \epsilon_{1} \delta_{1},
$$

there exists $u_{i} \in \operatorname{supp} \mu_{i}^{n}$ such that 
(ii) $\quad\left\|u_{i}-\hat{u}_{i}\right\|<\delta_{2}$

$$
\begin{aligned}
& \hat{u}_{i}(\bar{q})-\hat{u}_{i}(q) \geq u_{i}(\bar{q})-u_{i}(q)+\epsilon_{2}(\bar{q}-q) \text { for all } q \in\left[\bar{q}-\delta_{1}, \bar{q}\right] \\
& \hat{u}_{i}\left(\bar{q}-\delta_{1}\right)-\hat{u}_{i}(q) \geq u_{i}\left(\bar{q}-\delta_{1}\right)-u_{i}(q) \text { for all } q \in\left[0, \bar{q}-\delta_{1}\right] .
\end{aligned}
$$

This axiom basically requires that if the utility function over smoke rights is flat near the smoke rights endowment, there is a small credible deviation which makes the utility function steeper. We verify in Example 5 below that the set of economies satisfying this assumption is nonempty.

For technical reasons, we assume that the utility functions are uniformly bounded.

Axiom B4 (Boundedness): For all $n$, for all $i$, there exists $M>0$ such that $u_{i}\left(\bar{q}_{i}\right) \leq M$, for all $\omega$.

We also require this:

Axiom B5 (Independence or substitutes): For each $n, u_{1}, \ldots, u_{n}$ are independent random variables.

Consider a sequence of mechanisms $\Gamma^{\mathrm{n}}$. We have

Theorem 5: Assume truth-telling is an equilibrium of the revelation mechanism. Let $q^{\mathrm{n}}$ $=q\left(u_{1}, \ldots, u_{n}\right)$. Suppose also that $R(\cdot)$ is bounded by a constant $K$. If a sequence of mechanisms satisfies Axioms B1-B5, then $q^{\mathrm{n}}$ converges in probability to zero with respect to the probability measure $P$.

Proof: Suppose not. Then (dropping the subscripts on subsequences) there are numbers $\gamma_{1}$ and $\gamma_{2}>0$ such that $\mathrm{P}\left(\mathrm{q}^{\mathrm{n}}(\mathrm{u})>\gamma_{1}\right)>\gamma_{2}$ for all $\mathrm{n}$.

From the assumption that $R(\cdot)$ is bounded we have 


$$
\sum_{i}\left(m^{i}(u)-\bar{m}^{i}\right) \leq K \text { a.s. }
$$

Therefore,

$$
\sum_{i} E\left(m^{i}(u)-\bar{m}^{i}\right) \leq K .
$$

Let $r_{i(n)}=\min _{i} E\left(m^{i}(u)-\bar{m}^{i}\right)$. We then have $\mathrm{nr}_{\mathrm{i}(\mathrm{n})} \leq \mathrm{K}$.

Thus, $r_{i(n)} \rightarrow 0$, which implies that

$$
\mathrm{E}\left(\mathrm{m}_{\mathrm{i}(\mathrm{n})}(\mathrm{u})-\overline{\mathrm{m}}_{\mathrm{i}(\mathrm{n})}\right) \rightarrow 0
$$

where $i(n)$ denotes an agent with minimum monetary payoff. Without loss of generality, let $i(n)=$ 1 for all n. From (4.5) we have

$$
\mathrm{E}\left\{\mathrm{E}\left[\mathrm{m}_{1}(\mathrm{u})-\overline{\mathrm{m}}_{1} \mid \mathrm{u}_{1}\right]\right\} \rightarrow 0
$$

An implication of (4.6) is that the random variable in braces converges to zero in probability. (See Breiman (1968) pp. 33-34.) Thus, we have

$$
\mathrm{E}\left[\mathrm{m}_{1}(\mathrm{u})-\overline{\mathrm{m}}_{1} \mid \mathrm{u}_{1}\right] \stackrel{\mathrm{p}}{\rightarrow} 0 .
$$

Taking subsequences if necessary, we have

$$
\mathrm{E}\left(\mathrm{m}_{1}(\mathrm{u})-\overline{\mathrm{m}}_{1} \mid \mathrm{u}_{1}\right) \stackrel{\text { a.s. }}{\rightarrow} 0 \text {. }
$$

Recall that the utility functions are nondecreasing in smoke rights. Thus, $u_{1}\left(q_{1}(u)\right) \leq$ $\mathrm{u}_{1}\left(\overline{\mathrm{q}}_{1}\right)$ and we have 


$$
\mathrm{E}\left(\mathrm{u}_{1}\left(\overline{\mathrm{q}}_{1}\right)-\mathrm{u}_{1}\left(\mathrm{q}_{1}(\mathrm{u})\right) \mid \mathrm{u}_{1}\right) \geq 0 \text { a.s. }
$$

From Axiom B1 we have

$$
\mathrm{E}\left(\mathrm{m}_{1}(\mathrm{u})-\overline{\mathrm{m}}_{1} \mid \mathrm{u}_{1}\right) \geq \mathrm{E}\left(\mathrm{u}_{1}\left(\overline{\mathrm{q}}_{1}\right)-\mathrm{u}_{1}\left(\mathrm{q}_{1}(\mathrm{u})\right) \mid \mathrm{u}_{1}\right) \geq 0 \text { a.s. }
$$

Using (4.8) and (4.10), we have

$$
\mathrm{E}\left(\mathrm{u}_{1}\left(\overline{\mathrm{q}}_{1}\right)-\mathrm{u}_{1}\left(\mathrm{q}_{1}(\mathrm{u})\right) \mid \mathrm{u}_{1}\right) \stackrel{\text { a.s }}{\longrightarrow} 0
$$

Next, using the uniform boundedness axiom, B5, we have

$$
E\left\{E\left[u_{1}\left(q_{1}(u)\right)-u_{1}\left(\bar{q}_{1}\right) \mid u_{1}\right]\right\}=E\left[u_{1}\left(q_{1}(u)\right)-u_{1}\left(q_{1}\right)\right] \rightarrow 0
$$

which implies that

$$
\mathrm{u}_{1}\left(\mathrm{q}_{1}(\mathrm{u})\right)-\mathrm{u}_{1}\left(\overline{\mathrm{q}}_{1}\right) \stackrel{\mathrm{p}}{\rightarrow} 0 .
$$

Thus, we have established that, under the contradiction hypothesis, the utility function of some sequence of agents must be getting flat from the equilibrium allocation to the endowment of smoke rights. We now use the continuity axiom to choose $\delta>0$ so that $\|\mathrm{u}-\hat{\mathrm{u}}\|<\delta$ implies that

$$
\left|q_{1}(u)-q_{1}\left(u, u_{-1}\right)\right|<\frac{\gamma_{1}}{2}
$$

for all $u_{-1} \in U^{n-1}$, where, recall, $\gamma_{1}$ is defined by the contradiction hypothesis.

In the support axiom, let $\delta_{1}=\gamma_{1}$ and $\delta_{2}=\delta$, where $\delta$ is given by the continuity axiom. Then choose $\epsilon_{1}, \epsilon_{2}>0$ according to the support axiom. 
Next we show that the set of events $\omega \in \Omega$, such that output is larger than $\gamma_{1}$ and the utility function for agent 1 is flat, has positive measure. Let $A_{n}=\left\{\omega \mid q^{n}(\omega)>\gamma_{1}\right\}$, and let $B_{n}=$ $\left\{\omega \mid \mathrm{u}_{1}(\overline{\mathrm{q}})-\mathrm{u}_{1}\left(\overline{\mathrm{q}}-\gamma_{1}\right) \leq \epsilon_{1} \gamma_{1}\right\}$. We claim that $\mathrm{P}\left(\mathrm{A}_{\mathbf{n}}-\mathrm{B}_{\mathbf{n}}\right) \rightarrow 0$. To prove this claim, suppose not. Then, taking subsequences if necessary,

$$
\mathrm{P}\left(\omega \mid \mathrm{u}_{1}(\overline{\mathrm{q}})-\mathrm{u}_{1}\left(\overline{\mathrm{q}}-\gamma_{1}\right)>\epsilon_{1} \gamma_{1} \text { and } \mathrm{q}^{\mathrm{n}}>\gamma_{1}\right)
$$

is bounded away from zero. On this set of events, since $q^{n}>\gamma_{1}$ and $u$ is nondecreasing, using feasibility we have that

$$
\begin{gathered}
u_{1}(\bar{q})-u_{1}\left(q_{i(n)}(u)\right) \geq u_{1}(\bar{q})-u_{1}\left(\bar{q}-q^{n}(u)\right) \\
\geq u_{1}(\bar{q})-u_{1}\left(\bar{q}-\gamma_{1}\right)>\epsilon_{1} \gamma_{1} .
\end{gathered}
$$

Thus, $P\left(\omega \mid \mathrm{u}_{1}(\overline{\mathrm{q}})-\mathrm{u}_{1}\left(\mathrm{q}_{1}(\mathrm{u})\right)>\epsilon_{1} \gamma_{1}\right)$ is bounded away from zero, which contradicts (4.12). We have established that $P\left(A_{n}-B_{n}\right) \rightarrow 0$.

Next we construct a deviation for agent 1 . For the set of events $\omega$, such that $u_{1}(\bar{q})-$ $u_{1}\left(\bar{q}-\gamma_{1}\right) \leq \epsilon_{1} \gamma_{1}$, choose a measurable selection $K(u)$ from the nonempty set of deviations $\hat{u}$ defined in the support statement. (The measurable selection theorem in Hildenbrand (1974, p. 22) guarantees that such a selection is possible.) For all other events, let $K(\mathrm{u})=\mathrm{u}$. Note that $\mathrm{K}(\mathrm{u})$ is measurable with respect to the sigma algebra generated by agent 1's information.

Now calculate the expected utility for agent 1 from this deviating strategy relative to agent 1's endowment. This expected utility is given by

$$
\begin{aligned}
\mathrm{V}_{1} & =\mathrm{E}\left[\hat{\mathrm{m}}_{1}+\mathrm{u}_{1}\left(\hat{q}_{1}\right)-\left(\overline{\mathrm{m}}_{1}+\mathrm{u}_{1}\left(\overline{\mathrm{q}}_{1}\right)\right)\right] \\
& \left.=\mathrm{E}\left[\hat{\mathrm{m}}_{1}+\mathrm{u}_{1}\left(\hat{q}_{1}\right)-\left(\overline{\mathrm{m}}_{1}+\mathrm{u}_{1}\left(\overline{\mathrm{q}}_{1}\right)\right)\right] \mathrm{u}_{1}\right],
\end{aligned}
$$

where $\hat{\mathrm{m}}_{1}, \hat{\mathrm{q}}_{1}$ denote outcomes when agent 1 deviates. 
By construction the deviating strategy is in the support of $\mu_{\mathrm{i}}^{\mathrm{n}}$. Using individual rationality, we have

$$
\mathrm{E}\left\{\mathrm{E}\left(\hat{\mathrm{m}}_{1}+\hat{\mathrm{u}}_{1}\left(\hat{\mathrm{q}}_{1}\right)\right)-\left(\overline{\mathrm{m}}_{1}+\hat{\mathrm{u}}_{1}\left(\overline{\mathrm{q}}_{1}\right)\right) \mid \hat{\mathrm{u}}_{1}\right\} \geq 0
$$

Using (4.15) and the independence axiom, B5, we have that

$$
E\left\{E\left(\hat{m}_{1}\right) \mid u_{1}\right\} \geq E\left\{E\left(\bar{m}_{1}+\hat{u}_{1}\left(\bar{q}_{1}\right)-\hat{u}_{1}\left(\hat{q}_{1}\right)\right) \mid u_{1}\right\}
$$

Substituting (4.16) into (4.14), we have, after some simplification, that

$$
\mathrm{v}_{1} \geq E\left[\hat{\mathrm{u}}_{1}\left(\overline{\mathrm{q}}_{1}\right)-\hat{\mathrm{u}}_{1}\left(\hat{\mathrm{q}}_{1}\right)+\mathrm{u}_{1}\left(\hat{\mathrm{q}}_{1}\right)-\mathrm{u}_{1}\left(\overline{\mathrm{q}}_{1}\right)\right]
$$

Denote the expression in brackets by $W(\hat{u}, u)$. Then we have

$$
\mathrm{V}_{1} \geq \int_{\mathbf{B}_{\mathbf{n}}} \mathrm{W}(\hat{\mathrm{u}}, \mathrm{u}) \mathrm{d} \mu^{\mathrm{n}}+\int_{\mathbf{B}_{\mathbf{n}}^{\mathrm{c}}} \mathrm{W}(\hat{\mathrm{u}}, \mathrm{u}) \mathrm{d} \mu^{\mathrm{n}}
$$

By construction of $\hat{u}, W(\hat{u}, u)=0$ on the set $B_{n}^{c}$. Therefore, we have

$$
\mathrm{V}_{1} \geq \int_{\mathbf{B}_{\mathbf{2}} \cap \mathrm{A}_{\mathbf{2}}} \mathrm{W}(\hat{\mathrm{u}}, \mathrm{u}) \mathrm{d} \mu^{\mathbf{n}}+\int_{\mathbf{B}_{\mathbf{2}} \cap \mathrm{A}_{\mathbf{2}}^{\mathrm{c}}} \mathrm{W}(\hat{\mathrm{u}}, \mathrm{u}) \mathrm{d} \mu^{\mathbf{n}}
$$

Now, by construction of $\hat{u}, W(\hat{u}, u) \geq 0$. Thus, the second expression on the right in (4.19) is nonnegative. Consider the first expression. Now, by construction of $\hat{\mathrm{u}}$, we have

$$
\begin{gathered}
\mathrm{W}(\hat{\mathrm{u}}, \mathrm{u}) \geq \epsilon_{2} \gamma_{1} \text { if } \hat{\mathrm{q}}_{1}<\overline{\mathrm{q}}_{1}-\gamma_{1} \\
\geq \epsilon_{2}\left(\gamma_{1} / 2\right) \text { if } \hat{\mathrm{q}}_{1}>\overline{\mathrm{q}}_{1}-\gamma_{1} .
\end{gathered}
$$

Thus, we have

$$
V_{1} \geq \epsilon_{2} \frac{\gamma_{1}}{2} P\left(B_{n} \cap A_{n}\right)
$$


Recall that $P\left(B_{n} \cap A_{n}\right)$ is bounded away from zero. Thus, we have

(4.21) $\quad \mathrm{V}_{1} \geq \Delta_{\mathrm{n}}$

where $\Delta_{n}$ is bounded away from zero. But from (4.8) and (4.11) we have that

$$
\mathrm{E}\left(\mathrm{m}_{1}+\mathrm{u}_{1}\left(\mathrm{q}_{1}\right)\right)-\left(\overline{\mathrm{m}}_{1}+\mathrm{u}_{1}\left(\overline{\mathrm{q}}_{1}\right)\right) \rightarrow 0 .
$$

Thus, for sufficiently large n,

$$
E\left\{E\left(\hat{m}_{1}+u_{1}\left(q_{1}\right) \mid u_{1}\right)\right\}>E\left\{E\left(m_{1}+u_{1}\left(q_{1}\right) \mid u_{1}\right)\right\}
$$

Clearly, (4.23) contradicts the requirement that in a Bayesian Nash equilibrium there be no profitable deviations.

While this proof is fairly tedious, the intuition is straightforward. Because $R(\cdot)$ is bounded, some agent must be getting paid nothing eventually for giving up smoke rights. If such an agent can credibly claim to value smoke rights-that is, if the support statement is satisfied-then individual rationality requires positive payments to this agent. Thus, to prevent such deviations, the mechanism asymptotically requires no agent to sell smoke rights, and output converges to zero.

The independence assumption plays a more innocuous role than does the support assumption and can be relaxed. As should be clear from the proof (especially (4.15) and (4.16)), what we really use is that, for all $u$, for all $\hat{u}$, in the support of $\mu_{i}^{n}$,

$$
E\left\{m_{i}(\hat{a})+\hat{u}_{i}\left(q_{i}(u)\right) \mid u_{i}\right\} \geq \bar{m}_{i}+\hat{u}_{i}\left(q_{i}(u)\right) .
$$

This condition follows from independence and individual rationality. Alternatively, consider replacing (A1) by the requirement of ex-post voluntary trade 
Axiom B1' (Ex-post voluntary trade): For all $\mathrm{n}$, for all $\mathrm{i}$, the revelation mechanism satisfies

$$
m_{i}(u)+u_{i}\left(q_{i}(u)\right) \geq \bar{m}_{i}+u_{i}\left(\bar{q}_{i}\right) \text { for all } u \in \operatorname{supp} \mu^{n}
$$

Suppose a sequence of mechanisms satisfies B1' and B2 through B4, but not necessarily the independence Axiom B5. Then, the proof of Theorem 5 is essentially unchanged, except that (4.15) implies (4.16) in the proof from B1'. We have proved the following theorem.

Theorem 6. Assume truth-telling is an equilibrium of the revelation mechanism. Let $q^{n}=q\left(u_{1}, \ldots, u_{n}\right)$. Suppose also that $R(\cdot)$ is bounded by a constant $k$. If a sequence of mechanisms satisfies $B 1^{\prime}$, and B2 through B4, then $q^{n}$ converges in probability to zero.

Alternatively, we would directly impose (4.24) as an axiom on the mechanisms.

\section{Comments and Examples}

(xiii) With no private information, there are clearly many environments for which efficient outcomes are bounded away from zero. With private information, however, interim efficient mechanisms (defined as in Holmstrom and Myerson (1983)) cannot punish individuals too severely for small deviations from truth-telling. Hence, it is possible that all interim efficient mechanisms yield zero output in the limit. (See Rob (1989) for a result of this kind.) We construct an example to show that interim efficient mechanisms need not yield zero output in the limit. The example also demonstrates the role of uniform continuity in Theorem 5.

Example 4: Suppose the utility functions are given by

$$
\mathrm{U}_{\mathrm{i}}(\mathrm{m}, \mathrm{q})=\mathrm{m}-\theta_{\mathrm{i}} \mathrm{q}
$$


where $\theta_{\mathbf{i}}$ is identically, independently distributed across $\mathrm{i}$. The random variable $\theta_{\mathbf{i}}$ is distributed uniformly over $[0,1 / n]$ with density $p_{n}$ and uniformly over $[1 / n, 1]$ with density $r_{n}$ given by

$$
r_{\mathbf{n}}=\frac{\left(1-p_{n} / n\right)}{(1-1 / n)}
$$

Note that we have written the utility function directly as a function of output rather than as a function of smoke rights.

The inverse demand function is given by

$$
D^{-1}(q)=4-q
$$

Our aim is not to characterize incentive-efficient mechanisms. Rather, we construct a particular mechanism for which the sum of the expected utilities over all individuals is bounded away from zero with positive probability. Thus, we restrict attention to efficient mechanisms which maximize the sum of the expected utilities of the agents. If such efficient mechanisms yield zero output in the limit, they yield zero utility. Then we have a contradiction and, therefore, the desired result.

Consider, therefore, the following mechanism. If all agents report $\theta_{i} \in[0,1 / \mathrm{n}]$, then $q=1$; otherwise, $q=0$. Each agent receives an equal share of the revenues.

It is clear that for any consumer $i$, if $\theta_{i} \leq 1 / n$, then a (weakly) dominant strategy is to report the true value of $\theta$. Hence, in this case, payoffs must satisfy

$$
\mathrm{E}\left[\mathrm{V}_{\mathrm{i}}^{\mathrm{n}} \mid \theta_{\mathrm{i}} \leq 1 / \mathrm{n}\right] \geq\left(\mathrm{p}_{\mathrm{n}} / \mathrm{n}\right)^{\mathrm{n}-1}\left(3 / \mathrm{n}-\theta_{\mathrm{i}}\right)
$$

The sum of the expected utilities then satisfies

$$
\sum_{i=1}^{n} E\left(V_{i}^{n} \mid \theta_{i} \leq 1 / n\right) \geq\left(p_{n} / n\right)^{n-1}\left(3-\Sigma \theta_{i}\right) \geq 2\left(p_{n^{n}} / n\right)^{n-1}
$$


Clearly, many sequences $p_{n}$ yield welfare levels bounded away from zero. For example, suppose $\mathrm{p}_{\mathrm{n}}=\mathrm{n} \pi^{1 / \mathrm{n}}$, where $0<\pi \leq 1$. Then

$$
\lim _{n \rightarrow \infty} \sum_{i=1}^{n} \mathrm{EV}_{i}^{\mathrm{n}} \geq 2 \pi
$$

Furthermore, the probability that $\theta_{\mathbf{i}} \leq 1 / \mathrm{n}$ for all $\mathrm{i}$ converges to a positive number $\pi$. Efficient mechanisms must yield at least as high a utility level. Hence, the output of smoke cannot converge to zero. Efficient mechanisms in this example violate Axiom B2. The particular mechanism we consider is discontinuous at $\theta_{\mathbf{i}}=1 / \mathrm{n}$. However, it is straightforward to prove that for fixed $n$, the efficient mechanism yields output levels which are continuous in $\theta$. But this sequence of mechanisms does not yield output levels uniformly continuous in $\theta$.

(xiv) We now show that the space of utility functions satisfying the support assumption is nonempty. Consider the following example.

Example 5: Suppose the utility functions over smoke rights are given by

$$
\mathrm{u}_{\mathrm{i}}\left(\mathrm{m}, \mathrm{q}_{\mathrm{i}}\right)=\mathrm{m}+\theta_{\mathrm{i}} \mathrm{q}_{\mathrm{i}}
$$

where $\theta_{\mathbf{i}}$ is a random variable identically, independently distributed across $\dot{i}$. The distribution function from which $\theta_{\mathrm{i}}$ is drawn is described by a strictly positive density $p_{\mathrm{n}}$ on $[0, \mathrm{~d}]$. Note that the support of the sequence of distributions is the same for all $\mathrm{n}$ though the distribution itself is permitted to vary with $\mathrm{n}$. To see that this example satisfies our support assumption, let $\epsilon_{1}=\mathrm{d} / 2$ and let $\epsilon_{2}$ $=\min \left(\mathrm{d} / 4, \delta_{2} / 2\right)$. Then $u_{\mathrm{i}}(\overline{\mathrm{q}})-\mathrm{u}_{\mathrm{i}}\left(\overline{\mathrm{q}}-\delta_{1}\right) \leq \epsilon_{1} \delta_{1}$ implies that $\theta_{\mathrm{i}} \leq \mathrm{d} / 2$. Clearly, the deviation $\hat{\theta}_{\mathrm{i}}=\theta_{\mathrm{i}}+\epsilon_{2}$ is in support of the distribution function and satisfies the slope conditions, (iii) and (iv) 
of the support axiom. This example demonstrates that in proving Theorem 5 we do not need to construct deviations for all draws of the utility function; rather, we need to construct deviations only for sufficiently flat utility functions.

(xv) Our assumptions that certain properties of mechanisms hold everywhere in the support are stronger than necessary. In particular, they can be replaced with (more cumbersome) probabilistic statements. For example, rather than requiring that the Interim Voluntary Trade axiom hold everywhere in the support, we could require that this axiom hold almost surely. We would then replace the support condition by requiring roughly that conditional on part (i) of the support axiom holding the set of events such that parts (ii), (iii), and (iv) of the support axiom hold has positive probability. More formally, we would require the following:

$$
\begin{aligned}
& \mathrm{P}\left(\omega | \text { (i) holds and } \mathrm { P } \left(\omega^{\prime} \mid \text { (ii), (iii), (iv) hold) }>0\right.\right. \text { ) } \\
& \quad=\mathrm{P}(\omega \mid \text { (i) holds). }
\end{aligned}
$$

Similarly, our condition that supp $\mu^{\mathrm{n}}=\mathrm{X}_{\mathrm{i}}$ supp $\mu_{\mathrm{i}}^{\mathrm{n}}$ can be relaxed.

\section{Alternative Property Rights}

Our results emphasize the role of monopoly power in producing inefficient outcomes. However, the economy considered in Section 3 has two sources of monopoly power. First, the distribution of endowments, or property rights, gives each consumer monopoly power over smoke produced at his or her location. Second, each person cares only about smoke produced over his or her location. Thus, there is a source of monopoly power arising from preferences. We wish to disentangle the effects of these two sources. A natural approach (suggested by Coase's paper) is to examine the provision of public goods under alternative property rights distributions. In particular, since we wish to understand the problem caused by monopoly power arising from preferences, it is convenient to endow individuals outside the town with smoke rights and have them behave 
competitively. This way of setting up the environment eliminates the monopoly power arising from ownership. This is also what we did in Example 2 and we want to generalize the results in that example. We can think of the individuals who own the smoke rights as caring about neither the smoke nor the final good. Alternatively, we can think of the government auctioning off the smoke rights.

We show that if the town has many residents, each of whom cares very little about smoke (although the aggregate loss may be significant), the residents don't buy any of the smoke rights. As before, we consider only revelation games. The strategy space for each player $i$ is given by $U_{B}$, which consists of nondecreasing functions on $[0, Q]$ such that for all $x, \hat{x} \in[0, Q],\left|u_{i}(x)-u_{i}(\hat{x})\right|$ $\leq B / n|x-\hat{x}|$. These functions are interpreted as utility from smoke rights. Let $U_{n}^{B}=U_{B} \times \ldots$ $\times U_{B}$, where $n$ is the number of residents in the town. We define a mechanism slightly differently here than we did earlier.

We first describe the outcome functions that constitute a mechanism. The same quantity of smoke rights is issued for each location and is denoted by $\bar{q}$. The amount of smoke produced is denoted by $q(t)$. Denote the consumption of smoke rights at location $j$ by consumer $i$ by $x_{j}^{j}(t)$. Smoke rights not purchased by consumers are retained by the government or the demand sector of the economy and are used to produce smoke. Consumers in the town pay $\mathrm{p}_{\mathrm{i}}(\mathrm{t})$ per unit of smoke rights at location i. A mechanism is then defined as a set of outcome functions $p(t), x(t)$, and $q(t)$ satisfying

$$
\sum_{i=1}^{n} x_{j}^{i}(t)=\bar{q}-q(t)
$$$$
(\mathrm{j}=1, \ldots, \mathrm{n})
$$

and

$$
\sum_{i=1}^{n} p_{i}(t) \sum_{j=1}^{n} x_{i}^{j}(t)+R(q(t))=\bar{q} \sum_{i=1}^{n} p_{i}(t)
$$


For convenience, let $\mathrm{q}_{\mathrm{i}}=\mathrm{x}_{\mathrm{i}}^{\mathrm{i}}$.

Equation (5.2) deserves some comment. Implicit in this feasibility condition is the assumption that the government or the demand sector values the initial distribution of smoke rights at the prices of smoke rights at each location. Thus, in effect, the mechanism does not permit price discrimination between the residents of the town and the owners of the smoke rights. Then, the term on the right side of (5.2) is revenues from the sale of smoke rights and the first term on the left is total expenditures by town residents on smoke rights. Because production of a unit of output requires one unit of smoke rights at each location, and because smoke rights are the only input to production, the revenues from production are used entirely to purchase smoke rights. Equation (5.2) then follows.

Suppose that the sequence of mechanisms satisfies these axioms:

Axiom $\mathrm{C} 1$ (Voluntary trade): For all $\mathrm{n}$, for all $\mathrm{i}=1, \ldots, \mathrm{n}$, and for all $\mathrm{t} \in \mathrm{U}_{\mathrm{B}}^{\mathrm{m}}$, $t_{i i}\left(q_{i}(t, n) ; n\right)-\sum_{j} p_{j}(t, n) x_{j}^{i}(t, n) \geq 0$

Axiom C2 (Lipschitz continuity): For all $n$, and for all $i=1,2, \ldots, n$, there exists $A>0$ such that for all $t, \hat{t} \in U_{B}^{n},\left|q_{i}(t, n)-q_{i}\left(\hat{t}_{i}, t_{-i}, n\right)\right| \leq A\left\|t_{i}-\hat{t}_{i}\right\|$, where $\|\cdot\|$ is the sup-norm.

We now prove that decentralized mechanisms lead to inefficient outcomes. Theorem 7 (Decentralized mechanisms in public goods environments yield inefficient outcomes): Consider a sequence of utility functions for consumers in $U_{\mathrm{B}}$. Assume that the domain of the revelation mechanism is $U_{\mathrm{B}}^{\mathrm{m}}$ for each $n$. Denote the equilibrium amounts of smoke rights at location $j$ bought 
by consumer $i$ by $x(i, j, n)$ and the price per smoke right by $p(j, n)$. If a sequence of mechanisms satisfies Axioms $C 1$ and $C 2$, then

$$
\lim _{n \rightarrow \infty} \sum_{j} p(j, n) \sum_{i} x(i, j, n)=0 .
$$

Proof: We first show that

$$
\lim _{n \rightarrow \infty} n\left[\max _{i} \sum_{j} p(j, n) x(i, j, n)\right]=0
$$

The theorem then follows immediately. Suppose, therefore, that (5.3) does not hold. Again, choose subsequences if necessary and drop the subscript on the subsequence. There is some sequence of consumers $i_{\mathfrak{n}}$ whose expenditures are maximal over all consumers such that

$$
\lim _{n \rightarrow \infty} n \sum_{j} p(j, n) x\left(i_{n}, j, n\right)=d>0 .
$$

Without loss of generality, let $i_{n}=1$ for all $n$.

Consider the following deviation for consumer 1. Let $\hat{t}_{11} \equiv 0$. From Axiom $\mathrm{C} 1$ we have that total expenditures by consumer 1 are zero for all $n$. Hence, the difference in utilities between this deviation and truth-telling is

$$
\Delta_{n}=V_{1}(\hat{t} ; n)-V_{1}(t ; n)=u_{1}\left(\hat{q}_{1}^{n} ; n\right)-u_{1}\left(q_{1}^{n} ; n\right)+\sum_{j} p(j, n) x(1, j, n),
$$

where $\hat{q}_{1}^{n}=q_{1}\left(t_{-1}, \hat{t}_{1}, n\right)$ and $q_{1}^{n}$ is defined similarly. If $\hat{q}_{1}^{n}>q_{1}^{n}$, then (5.4) is positive and $q_{1}^{n}$ cannot be an equilibrium outcome. Therefore, $\hat{q}_{1}^{n} \leq q_{1}^{n}$. Since the utility functions lie in $U_{B}$,

$$
\mathrm{n} \Delta_{\mathrm{n}} \geq \mathrm{B}\left(\mathrm{q}_{1}^{\mathrm{n}}-\mathrm{q}_{1}^{\mathrm{n}}\right)+\mathrm{n} \sum_{\mathbf{j}} \mathrm{p}(\mathrm{j}, \mathrm{n}) \mathrm{x}(1, \mathrm{j}, \mathrm{n}) .
$$

From Axiom $\mathrm{C} 2$ we have that $\left|\hat{\mathrm{q}}_{1}^{\mathrm{n}}-\mathrm{q}_{1}^{\mathrm{n}}\right| \leq(\mathrm{AB} / \mathrm{n}) \mathrm{Q}$. Therefore, $\mathrm{n}$ can be chosen large enough so that $n \Delta_{n}>0$. We have a contradiction. 
We have shown that total expenditures on smoke rights converge to zero. This implies (given our assumption of finite reservation price) that either the sum of the prices converges to zero or purchases of smoke rights converge to zero. If the sum of the prices converges to zero, it follows from (5.2) that production of smoke converges to zero, which is clearly inefficient in general. If purchases of smoke rights converge to zero, then outcomes are inefficient unless the government happens to auction off exactly the efficient quantity of smoke rights. We consider the case where the amount of smoke rights auctioned off depends upon the reported types below.

While we do not explore this here, analogues of Theorems 5 and 6 presumably also hold in this environment with private information.

\section{The Free-Rider Problem Revisited}

As the discussion following Theorem 4 in Section 3 indicates, our setting up the public goods problem in a privatized economy does not fundamentally affect our results. The preferences of consumers in this public goods economy are given by

$$
m_{i}-v_{i}(q) .
$$

The individual rationality condition associated with Axiom $\mathrm{C} 1$ for this public goods economy is now

Axiom $\mathrm{C1}^{\prime}$ (Individual rationality): For all $\mathrm{n}$, for all $\mathrm{i}=1, \ldots, \mathrm{n}$, for all $\mathrm{t} \in \mathrm{U}^{\mathrm{n}}$, $m_{i}(t, n)-v_{i}(q(t, n) ; n) \geq \bar{m}_{i}-v_{i}(\bar{q} ; n)$.

In effect, in this public goods economy, reducing the quantity of smoke requires unanimous consent. The relationship between the public goods and the private goods economies can be seen by simply defining

$$
u_{i}\left(x_{i}^{i}-\bar{q}\right)=-v_{i}(q) .
$$


Again, the public goods formulation makes the free-rider problem clearer. The private goods formulation emphasizes the role of monopoly power. Because the results are the same, the two problems are equivalent.

\section{Endogenous Property Rights Distributions}

Thus far we have assumed that the initial distribution of smoke rights is fixed. We now ask whether decentralized mechanisms can solve the public goods problem when the initial distribution is endogenously determined. To answer this question, we consider mechanisms in which the quantity of smoke rights issued depends upon the vector of reported utility functions. We denote the smoke rights issue function by $\bar{q}(u)$. We assume that this function is uniformly bounded by $\overline{\mathrm{Q}}$. The preferences of consumer $i$ are given by $m_{i}+u_{i}\left(q_{i}-\bar{q}\right)$, where $m_{i}$ denotes money, $q_{i}$ denotes consumption of smoke rights at location $i$, and $\bar{q}$ denotes the amount of smoke rights issued.

Suppose that the sequence of mechanisms satisfies these axioms:

$\underline{\text { Axiom } C 1^{\prime \prime}}$ (Voluntary trade): For all $n$, for all $i=1, \ldots, n$, and for all $t \in U_{B}^{n}$,

$$
t_{i i}\left(q_{i}(t)-\bar{q}(t) ; n\right)-\sum_{j} p_{j}(t, n) x_{j}^{i}(t, n) \geq t_{i i}(-\bar{q}(t) ; n)
$$

Axiom $\mathrm{C2}^{\prime}$ (Lipschitz continuity): For all $\mathrm{n}$ and for all $\mathrm{i}$, for all $\mathrm{t}, \hat{\mathrm{t}} \in \mathrm{U}_{\mathrm{B}}^{\mathrm{n}}$, there exists $A>0$ such that

$$
\left|y_{i}\left(t_{-i}, t_{i}, n\right)-y_{i}\left(t_{-i}, \hat{t}_{i}, n\right)\right| \leq A\left\|t_{i}-\hat{t}_{i}\right\|
$$

where

$$
\mathrm{y}_{\mathrm{i}}(\cdot, \mathrm{n})=\mathrm{q}_{\mathrm{i}}(\cdot, \mathrm{n})-\overline{\mathrm{q}}_{\mathrm{i}}(\cdot, \mathrm{n})
$$

and $\|\cdot\|$ is the sup-norm. 
It is easy to see that Theorem 7 holds with no change at all. Therefore, residents do not buy any smoke rights. The only issue still to be addressed is under what conditions $\bar{q}(t, n)$ will be chosen to yield efficient outcomes.

To explore this question, we consider mechanisms in which $\mathrm{q}_{\mathrm{i}}(t, \mathrm{n}) \equiv 0$ for all $t$ and for

all $\mathrm{n}$. That is, since we know that in the limit, residents do not buy any smoke rights, we assume from the outset that they need not purchase any. We show that if $\bar{q}(t, n)$ is sensitive to individuals' reports of their true types for such mechanisms, then the outcomes will be inefficient. Let $\bar{q}(t, n)=$ $\mathrm{g}\left(\sum \mathrm{t}_{\mathrm{ii}}\right)$, where $\mathrm{g}$ is a continuous, nonincreasing function. Then, clearly, each individual has an incentive to announce that his or her type is $(B / n) x$ regardless of the truth, and outcomes will, in general, be inefficient.

\section{Concluding Comments}

(xvi) The appeal of the results in Sections 3-5 is that they show that a large class of theories of the workings of markets give rise to the same prediction: In large economies with decentralized systems, problems caused by externalities lead to outcomes far from the efficient level. Two assumptions play a key role in our analysis. First, we require a strong voluntary trade axiom. Second, we require that the mechanisms be uniformly continuous in the actions of consumers. We call a sequence of mechanisms which satisfy these assumptions a theory of decentralized markets. Examples 1 through 3 and comments (viii) through (x) suggest the sense in which market-like arrangements satisfy our axioms. Comment (xi) provides examples of mechanisms which yield good outcomes and provides an indication of the sense in which such mechanisms are centralized. Therefore, we think that our axioms are a reasonable way to capture decentralized market interactions. Our results imply that mechanisms that yield good outcomes in economies with externalities must necessarily contain rules restricting the actions of private agents. Our results also 
suggest that the search for such mechanisms is exceedingly important precisely because unfettered markets are likely to function very badly in providing pure public goods. Although decentralized theories lead to inefficient outcomes with global externalities, Example 3 suggests that if externalities are local it may be possible to construct decentralized theories which yield efficient outcomes. (See also Chari and Jones (1989).)

(xvii) The results in Section 4 reemphasize the role of monopoly power in generating our results. When tastes are private information, even fairly weak notions of property rights grant substantial monopoly power to individuals. For example, when preferences are independent random variables, a person who demands a high price for his or her rights may well have a high valuation for the rights and a mechanism which respects the privacy of that valuation must necessarily grant substantial monopoly power. Of course, as Example 4 indicates, this monopoly power by itself need not lead to inefficient outcomes. The uniform continuity requirement plays an important role in our results by limiting the extent to which an individual can affect the allocations received by other individuals.

(xviii) The problems raised here are clearly present in the context of pure public goods as well. As should be clear, one difference between the externalities case and the public goods case is that, with public goods, the associated private goods economy contains perfectly complementary outputs rather than inputs.

In fact, the results in Section 5 can be easily reinterpreted as applying to the case of pure public goods. (Indeed, this is the interpretation Roberts (1976) gives in his work.) Simply set initial endowments at zero (as in Section 5) and reinterpret $R(q)$ as a cost function rather than a revenue function. This reinterpretation demonstrates one difference between public goods and externalities, namely, that in a public goods economy there is no need to assign initial endowments. 
Consequently, the market power which leads to inefficiencies arises solely from the uniqueness of preferences.

(xix) Our interpretation of Coase is but one of many (rivaling that of Keynes, we're sure). Of course, nothing as explicit as our analysis appears in Coase's paper. Certainly, Coase never mentions adding markets as the solution to the externalities problem. The notion that the problem is essentially one of missing markets appears explicitly as a definition in Heller and Starrett (1976) and is often attributed to Arrow (1970) but can probably be traced farther back, at least in some form. Something very close to this notion appears in Meade (1952) and is one interpretation of Lindahl (1919).

Of course, the contention that the whole problem with externalities is one of missing markets is not the view we have adopted in this paper. Quite the contrary, the question we have considered is, once property rights are fully distributed (which we do not deny is difficult to do), is the outcome likely to be efficient? That is, do economies with public goods or externalities (or both) present a significantly more severe problem for decentralization through self-interested voluntary exchange than economies with only private goods? The results of Sections 3-5 suggest that the answer to this question is that they do. However, Example 3 suggests that these problems may not be universal.

Another interpretation of Coase is that the distribution of legal rights does not have any effect on allocations. Clearly, this is true in many of his examples, but it cannot be considered seriously because it will not hold except in very special circumstances (e.g., when the income distribution does not affect equilibrium allocations). That is, the only reasonable interpretation is that all equilibria are efficient, but that different distributions of initial property rights may give rise to alternative efficient allocations. 
Green (1982) gives a very interesting interpretation of Coase in terms of the efficiency of equilibria of legal structures. He gives conditions under which all efficient outcomes are equilibria of the legal system. In this framework, the Coase Theorem would state that all equilibria of the legal system are efficient. This is an interesting approach to the problem, but we know of no attempt to prove the Coase Theorem as stated above.

(xx) The problem set forth in the examples of Section 2 has another analogue in economics, namely, the problem of eminent domain (that being the commonly used solution). Suppose that a city decides to build a new civic center (or highway). To do this, it must displace all residents in the area of the proposed site. If current owners are compensated by paying them what they announce is the value of their lots, they have a strong incentive to overstate the value of their property to try to extract all the surplus from the arrangement. Again, because the lots are perfectly complementary given the site, the same monopoly problem arises. Example 3 also has a natural interpretation in this context: if there are many equally opportune sites, competition among them should give rise to efficient outcomes.

(xxi) Our approach to the problems we have considered has been to sacrifice complexity in the environments in favor of generality in the class of theories allowed. In doing so, we have made many special assumptions concerning preferences, technologies, etc. The importance of these restrictions naturally comes into question. In particular, it would be interesting to know whether our results generalize in a number of directions, including dropping the special structure of preferences to allow income effects, etc; allowing for more goods, both private and public; and allowing for pollution technologies in which partial exclusion is possible. In our view, the most important generalizations of the results obtained to this point would involve extensions along the lines of 
Example 3. Ideally, one would like a set of conditions under which most theories give rise to efficient outcomes in economies with local public goods and many potential locations.

This reasoning leads one naturally to consider alternative formulations of Tiebout's (1956) hypothesis. Note that the result given in Example 3 differs from the explanation offered by Tiebout in at least one important way: Mobility is extremely limited. That is, we do not allow agents to move at all (although output of the final good is allowed to move freely). This lack of mobility leaves open the possibility that the residents of a given town may be able to exploit monopoly power relative to one another. This feature can give rise to inefficiencies even with local public goods. (See Chari and Jones (1989).) These considerations lead one naturally to consider (as Tiebout does) models in which town formation itself is endogenous. In this regard, the recent work by Scotchmer (1985), Wooders (1986), and Scotchmer and Wooders (1986) contains useful insights. 


\section{REFERENCES}

Arrow, K. (1970): “The Organization of Economic Activity: Issues Pertinent to the Choice of Market Versus Non-Market Allocation," in Public Expenditures and Policy Analysis, ed. R. Haveman and J. Margolis. Chicago: Markham.

Breiman, L. (1968): Probability. Reading, Mass.: Addison-Wesley.

Chari, V. V., and L. E. Jones (1989): “A Reconsideration of the Problem of Social Cost: The Case of Local Public Goods," manuscript, Federal Reserve Bank of Minneapolis.

Coase, R. (1960): “The Problem of Social Cost," Journal of Law and Economics, 3, 1-44.

Cournot, A. (1838): Recherches sur les Principles Mathematics de la Theory des Richesse. Paris: M. Riviere.

Foley, D. (1967): "Resource Allocation and the Public Sector," Yale Economic Essays, 43, 43-98.

Green, E. (1982): “Equilibrium and Efficiency Under Pure Entitlement Systems,” Public Choice, $39,185-212$.

Groves, T., and J. Ledyard (1977): "Optimal Allocation of Public Goods: A Solution to the 'Free Rider' problem," Econometrica, 45, 783-809.

- (1985): “Incentive Compatibility Ten Years Later," Discussion Paper 648, Center for Mathematical Studies in Economics and Management Science, Northwestern University.

Hart, O. (1979): "Monopolistic Competition in a Large Economy With Commodity Differentiation," Review of Economic Studies, 46, 1-30.

- (1980): “Perfect Competition and Optimal Product Differentiation," Journal of Economic Theory, 22, 279-312.

Heller, W., and D. Starrett (1976): "On the Nature of Externalities," in Theory and Measurement of Externalities, ed. S. Lin. New York: Academic Press. 
Hildenbrand, W. (1974): Core and Equilibria of a Large Economy. Princeton, N.J.: Princeton University Press.

Holmstrom, B., and R. Myerson (1983): "Efficient and Durable Decision Rules With Incomplete Information," Econometrica, 51, 1799-1819.

Hurwicz, L. (1972): “On Informationally Decentralized Systems,” in Decision and Organization: A Volume in Honor of Jacob Marschak, ed. C. McGuire and R. Radner. Amsterdam: North-Holland.

Jones, L. (1987a): “The Efficiency of Monopolistically Competitive Equilibria in Large Economies: Commodity Differentiation With Gross Substitutes,” Journal of Economic Theory, 41, 356-391. (1987b): "Optimum Product Diversity and the Incentives for Entry in Large Economies," Quarterly Journal of Economics, 102, 595-614.

Lindahl, E. (1919): "Positive Losung, Die Gerechtigkeit der Besteuering," translated as "Just Taxation-A Positive Solution," in Classics in the Theory of Public Finance, ed. R. Musgrave and A. Peacock. London: MacMillan.

Mas-Colell, A. (1975): “A Model of Equilibrium With Differentiated Commodities," Journal of Mathematical Economics, 2, 263-295.

Makowski, L. (1980): “A Characterization of Perfectly Competitive Economies With Production,” Journal of Economic Theory, 22, 208-222.

Meade, J. (1952): “External Economies and Diseconomies in a Competitive Situation," Economic Journal, 62, 654-671.

Milleron, J. (1972): “Theory of Value With Public Goods: A Survey Article," Journal of Economic Theory, 5, 419-477. 
Rob, R. (1989): “Pollution Claim Settlements Under Private Information," Journal of Economic Theory, 47, 307-333.

Roberts, D. J. (1976): “The Incentives for Correct Revelation of Preferences and the Number of Consumers” Journal of Public Economics, 6, 359-374.

Rubinstein, A. (1982): “Perfect Equilibrium in a Bargaining Model," Econometrica, 50, 97-110.

Samuelson, P. (1954): “The Pure Theory of Public Expenditures," Review of Economics and Statistics, 36, 387-389.

Scotchmer, S. (1985): “Profit Maximizing Clubs,” Journal of Public Economics, 27, $25-45$.

Scotchmer, S., and M. Wooders (1986): “Optimal and Equilibrium Groups," Discussion Paper 1251, Harvard University.

Sonnenschein, H. (1983): "The Economics of Incentives: An Introductory Account," Nancy L. Schwartz Memorial Lecture, Northwestern University.

Starrett, D. (1972): "Fundamental Nonconvexities in the Theory of Externalities," Journal of Economic Theory, 4, 180-199.

Tiebout, C. (1956): “A Pure Theory of Local Expenditures," Journal of Political Economy, 64, 416-424.

Wooders, M. (1986): “A Tiebout Theorem,” Discussion Paper, University of Toronto. 